\title{
The Influence of Thermodynamic Ideas on Ecological Economics: An Interdisciplinary Critique
}

\section{Geoffrey P. Hammond ${ }^{1,2, *}$ and Adrian B. Winnett ${ }^{1,3}$}

1 Institute for Sustainable Energy \& the Environment $(I \cdot S E E)$, University of Bath, Bath, BA2 7AY, UK

2 Department of Mechanical Engineering, University of Bath, Bath, BA2 7AY, UK

3 Department of Economics, University of Bath, Bath, BA2 7AY, UK; E-Mail: hssabw@bath.ac.uk

* Author to whom correspondence should be addressed; E-Mail: ensgph@bath.ac.uk; Tel.: +44-12-2538-6168; Fax: +44-12-2538-6928.

Received: 10 October 2009 / Accepted: 24 November 2009 / Published: 1 December 2009

\begin{abstract}
The influence of thermodynamics on the emerging transdisciplinary field of 'ecological economics' is critically reviewed from an interdisciplinary perspective. It is viewed through the lens provided by the 'bioeconomist' Nicholas Georgescu-Roegen (1906-1994) and his advocacy of 'the Entropy Law' as a determinant of economic scarcity. It is argued that exergy is a more easily understood thermodynamic property than is entropy to represent irreversibilities in complex systems, and that the behaviour of energy and matter are not equally mirrored by thermodynamic laws. Thermodynamic insights as typically employed in ecological economics are simply analogues or metaphors of reality. They should therefore be empirically tested against the real world.
\end{abstract}

Keywords: thermodynamic analysis; energy; entropy; exergy; ecological economics; environmental economics; exergoeconomics; complexity; natural capital; sustainability 
"A theory is the more impressive, the greater the simplicity of its premises is, the more different kinds of things it relates, and the more extended is its area of applicability. Therefore the deep impression that classical thermodynamics made upon me. It is the only physical theory of universal content that, within the framework of applicability of its basic concepts, it will never be overthrown."

Albert Einstein, “Autobiographical Notes”, 1949

"What do you know of the Second Law of Thermodynamics? ... This law is one of the greatest depth and generality: it has its own sombre beauty: like all the major scientific laws, it evokes reverence. There is, of course, no value in a non-scientist just knowing it by the rubric in an encyclopaedia. It needs understanding, which can't be attained unless one has learnt some of the language of physics."

C P Snow, "The Two Cultures: A Second Look", 1964

"An orthodox economist ... would say that what goes into the economic process represents valuable natural resources and what is thrown out of it is valueless waste. But this qualitative difference is confirmed, albeit in different terms, by a particular (and peculiar) branch of physics known as thermodynamics. From the viewpoint of thermodynamics, matter-energy enters the economic process in a state of low entropy and comes out of it in a state of high entropy."

Nicholas Georgescu-Roegen, “The Entropy Law and the Economic Process”, 1971

\section{Background}

\subsection{Introduction}

Thermodynamic concepts or laws underpin the operation of energy systems that heat and power human development. Their scientific 'beauty', depth and generality (identified by C P Snow [1]) has inspired engineers and physical scientists over the last two centuries, including some of the very greatest, such as Albert Einstein. In the modern era, thermodynamic methods provide an important means of identifying process improvement potential, although heuristic developments have arisen in the past without the aid of science; as in the case of Watt's steam engine (which predated the development of the formal 'Laws of Thermodynamics' [2]). They utilise concepts like 'enthalpy' to represent the quantity of energy consumed, as well as 'exergy' to reflect its quality. But the related Second Law concept of entropy (an extensive property of matter) is not easy to grasp, particularly when it has been so widely used and abused. It was originally postulated by Rudolf Clausius (circa. 1864) via an analysis of the Carnot cycle for an ideal heat engine. This original 'energetic' (Clausius) entropy reflects the fact that, although heat can flow down a temperature gradient unaided, shaft work or an electrical energy input is required in order to induce heat transfer to take place from a cold to a hot reservoir: Clausius' inequality. However, idea of entropy has fascinated writers in disciplines far removed from engineering and the physical sciences.

Perhaps the first discipline outside engineering to seriously adopt thermodynamic ideas was economics; actually the sub-set that has become known as environmental economics $[3,4]$. The system studied in economics is the individual firm or the consumer. Transactions between the firm (or consumer) and the rest of the world are described in terms of the quantities and prices of the 
commodities exchanged. Prices in this neoclassical economic model are supposed to reflect the 'value' that society places on an economic good. Thus, economic practitioners claim that their discipline is 'normative': it suggests the optimal course of action to be taken in the allocation of resources, whereas thermodynamic analysis is 'descriptive'. However, environmental economists have employed thermodynamic ideas to devise alternative accounts of sustainability by analogy to physical or natural processes, such as energy usage. There is a well-developed literature, dating back to the early 1970s, that amounts to the postulation of an 'Energy Theory of Value' [5], although this has been largely rejected because choices about (First Law) energy use do not reflect the full complexity of human behaviour and value judgements. However, it was soon recognised that it is Second Law properties, such as entropy (and, by coupling with the First Law, exergy), which more realistically reflect dissipative processes. Nicholas Georgescu-Roegen (1906-1994), who in the latter part of his career regarded himself as a 'bioeconomist', was at the forefront of this movement with his advocacy of 'the Entropy Law' (his favoured expression for the Second Law of Thermodynamics; see Georgescu-Roegen [6]) as a measure of economic scarcity. Tribute is paid here to his contributions to the study of energy-matter as part of the economic process, although rather different conclusions are drawn about the utilisation of thermodynamic ideas in an attempt to understand natural resource scarcity and substitutability.

\subsection{The Issues Considered}

Thermodynamic concepts have been utilised by practitioners in a variety of disciplines with interests in environmental sustainability, including ecology, economics and engineering. It has been argued that resource depletion and environmental degradation are reflected in thermodynamic parameters and methods of analysis. But outside the realm of energy systems, thermodynamic concepts are typically employed by way of analogy [3], or as a metaphor [5]. Some resource economists, including Georgescu-Roegen [6], have viewed economic systems as ones in which energy is conserved, but in which entropy increases or exergy degrades. More recently, engineers in Europe and North America have proposed the coupling of exergy analysis with financial cost accounting; yielding the so-called 'exergoeconomic' approach. However, Hammond and Winnett [3] have recently cast doubt on such methods, which attempt to merge schema that may in large measure be incompatible - trying to mix 'chalk and cheese'. In this context, the influence of thermodynamic ideas on the development of the emerging, transdisciplinary field of 'ecological economics' will be critically reviewed from an interdisciplinary perspective.

\section{Science and Sustainability in a Complex World}

Over a period of some 15-20 years, the international community has been grappling with the task of defining the concept of 'sustainable development'. It came to particular prominence as a result of the so-called Brundtland Report published in 1987 under the title "Our Common Future"; the outcome of four years of study and debate by the World Commission on Environment and Development [7] led by the former Prime Minister of Norway, Gro Harlem Brundtland. This Commission argued that the time had come to couple economy and ecology, so that the wider community would take responsibility for 
both the causes and the consequences of environmental damage. It thereby attempts to balance economic and social development with environmental protection (encapsulated in the 'strapline' for the 2002 Johannesburg World Summit on Sustainable Development of "people, planet, prosperity"); the so-called 'triple bottom line' [8], or what others term 'The Three Pillars'. Many writers and researchers have acknowledged that the concept of 'sustainable development' is not one that can readily be grasped by the wider public (see, for example, Hammond [9]). However, no satisfactory alternative has thus far been found. Further confusion is added by the large number of formal definitions for sustainable development that can be found in the literature; Parkin [8] refers to more than two hundred.

The Brundtland Commission envisaged sustainable development as a means by which the global system would satisfy "the needs of the present without compromising the ability of future generations to meet their own needs" [7]. It therefore involves a strong element of intergenerational ethics; what John Gummer, former UK Secretary of State for the Environment (1993-1997), encapsulated in the popular phrase "don't cheat on your children" [8]. The interconnections between engineering constraints and the economic and social domain are illustrated by the sustainability Venn diagram shown in Figure 1 (Hammond [10]; adapted from a version originally developed by Clift [11] and extended by Parkin [8]). Here thermodynamic limits are represented as underpinning the environmental sphere. But the notion of sustainable development is not without its critics. Meredith Thring (Emeritus Professor of Mechanical Engineering at Queen Mary's College, London) regards the term as an oxymoron; arguing that development per se cannot be sustainable. He would prefer humanity to strive for a creative and stable world with the aid of 'equilibrium engineering' [12]. Similar views can be found in developing countries, where their debt burden and inequalities in global income distribution are seen as serious obstacles to sustainable development.

Figure 1. Venn diagram representation of 'The Three Pillars' of sustainability. Source: Hammond [10]; adapted from Clift [11] and Parkin [8].

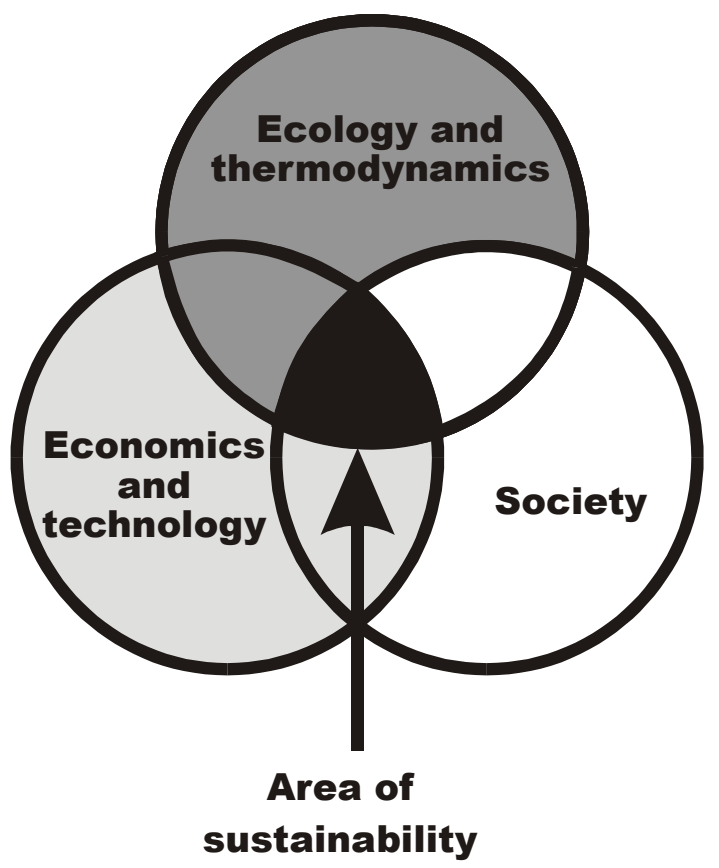


Both Sara Parkin [8] and Jonathan Porritt [13], British environmental campaigners and now co-Directors of Forum for the Future, have recently stressed that sustainable development is only a process or journey towards a destination: 'sustainability'. This end-game cannot easily be defined from a scientific perspective, although Porritt [13] argues that the attainment of sustainability can be measured against a set of four 'system conditions'. He draws these from 'The Natural Step' (TNS); an initiative by the Swedish cancer specialist, Karl-Henrick Robèrt (see, for example, Broman et al. [14]). One of TNS system conditions, for example, suggests that finite materials (including fossil fuels) should not be extracted at a faster rate than they can be redeposited in the Earth's crust. This contrasts with the present rapid rate of fossil fuel depletion on the global scale: 20-40 years for oil, 40-70 years for natural gas, and 80-240 years for coal [9]. Such sustainability requirements would put severe constraints on economic development, are extremely difficult to achieve in engineering terms, and they may therefore be viewed as being impractical; or 'utopian' (see, for example, Hammond [10]). They certainly imply that the ultimate goal of sustainability is rather a long way off when compared with the present conditions on the planet. Parkin [8] suggests 2050-2100 or beyond.

\section{Thermodynamics, Analogy and Metaphor}

Practitioners in a variety of disciplines with interests in environmental sustainability, including ecology, economics and engineering, have drawn on thermodynamic concepts (as noted in Section 1.2 above). Widespread concern about resource depletion and environmental degradation are common to them all these areas of study. It has been argued that the deleterious consequences of human development are reflected in thermodynamic ideas and methods of analysis (see, for example, the early work of Mueller [15] at the US Goddard Space Flight Center); they are said to mirror energy transformations within society. Mueller [15] draws a parallel between the resource flows in economics and energy (as well as implicitly exergy) flows in thermodynamics. This led him to an, arguably rather dubious, analogy between the "technology of man" and heat engines. Such ideas have inspired Parkin [8] and others to believe that thermodynamic principles or laws may act as a guide for engineers in the quest for environmental sustainability. In the context of 'The Natural Step', energy and matter are seen as having a tendency to disperse. Entropy (a Second Law extensive property of thermodynamic systems; see Section 4.5 below for further discussion) is regarded as a measure of this dispersal in a closed or isolated system. The Earth is such a closed system in terms of matter, but an open one from the perspective of the incoming solar energy that drives living plants via photosynthesis. This underpins the notion of 'capital' and 'income' energy resources for the planet (such as fossil fuels and solar energy respectively), and is behind TNS system condition that relates to the conservation of materials and fossil fuels. Outside the realm of energy systems, thermodynamic concepts are typically employed in terms of an analogy with, or resemblance to, physical processes [10]. Alternatively, their use may be regarded as metaphorical (see Scott and Gough [16] and Mirowski [17]): being imaginatively, but not literally, applicable.

An interesting feature of the advocacy of 'The Natural Step' system conditions in the present context is the claim that they reflect thermodynamic limits. Broman et al. [14] and others suggest that TNS conditions address the tendency of energy and matter to spread spontaneously. They in turn view this as mirroring the Second Law of Thermodynamics or what they, in common with 
Georgescu-Roegen [6], term 'The Entropy Law'. In reality, the latter property is what the distinguished American mechanical engineer Stephen J Kline (1922-1997) refers to as the 'vulgar' entropy; reflecting the generic, but vague or ill-defined, application of entropy to various kinds of disorder (see Kline [18], or the review of his book by Hammond [19]). The Natural Step, in effect, uses the Laws of Thermodynamics (according to Hammond [10]) only by way of a rather loose analogy, or as a metaphor. Indeed Upham [20] argues that TNS moves beyond (scientific and other) knowledge in signposting action for the business sector. He contends that it represents a political and ethical statement rather than any justifiable scientific consensus.

\section{The Mathematical and Physical Framework Provided by the 'Laws of Thermodynamics'}

\subsection{Energy Analysis}

The First Law of Thermodynamics is simply based on the principle of energy conservation, which in turn provides the foundations for 'energy analysis'. It may be represented for a steady-state process by the balance Equation [21]:

$$
\sum(\mathrm{h}+\mathrm{ke}+\mathrm{pe})_{\text {in }} \mathrm{m}_{\text {in }}-\sum(\mathrm{h}+\mathrm{ke}+\mathrm{pe})_{\text {out }} \mathrm{m}_{\text {out }}+\sum \mathrm{Q}-\mathrm{W}=0
$$

where $m_{\text {in }}$ and $m_{\text {out }}$ denote the mass flow across the system inlet and outlet respectively, $Q$ represents the heat transfer across the system boundary, $\mathrm{W}$ is the work (including shaft work, electricity, and so on) transferred out of the system, and h, ke, and pe denote the specific values of enthalpy, kinetic energy, and potential energy respectively. This energy balance (represented schematically in Figure 2 [10]) can be simplified, assuming negligibly small changes in kinetic and potential energy and no heat or work transfers, to [21]:

$$
\sum \mathrm{H}_{\mathrm{i}, \text { in }}=\sum \mathrm{H}_{\mathrm{j}, \text { out }}
$$

where $\mathrm{H}_{\mathrm{i} \text {.in }}$ represents the enthalpies of the various incoming flow streams for the system, and $\mathrm{H}_{\mathrm{j} \text {,out }}$ the different enthalpies outputs. Enthalpy is an extensive property of matter, which represents the energy content of the flow stream (or 'energy carrier' in lay person's terms), defined by:

$$
H_{2}-H_{1}=m c_{p}\left(T_{2}-T_{1}\right)
$$

where $\mathrm{m}$ is the mass flowrate of the stream, and $c_{p}$ is the specific heat at constant pressure of the working fluid. The suffices 1 and 2 indicate the start and end conditions for the cycle or process. It can be seen that there is an almost direct connection between enthalpy and the experimental measurements needed to determine its value. The mathematical manipulations associated with these measurements involve only linear algebra. These characteristics, and nearness of enthalpy to the direct human experience of heat transfer, make it easy to accept that its value is worth knowing [22].

If all these energy inputs and outputs for a system are taken into account (whether or not all the outputs are actually 'useful') then the First Law energy efficiency becomes:

$$
\eta=\sum \mathrm{E}_{\mathrm{j}, \text { out }} / \sum \mathrm{H}_{\mathrm{i}, \mathrm{in}}=\mathrm{H}_{\text {out }} / \mathrm{H}_{\mathrm{in}}=1
$$


Figure 2. An energy balance for a simple control volume or unit operation. Source: Hammond [13]; upgraded.

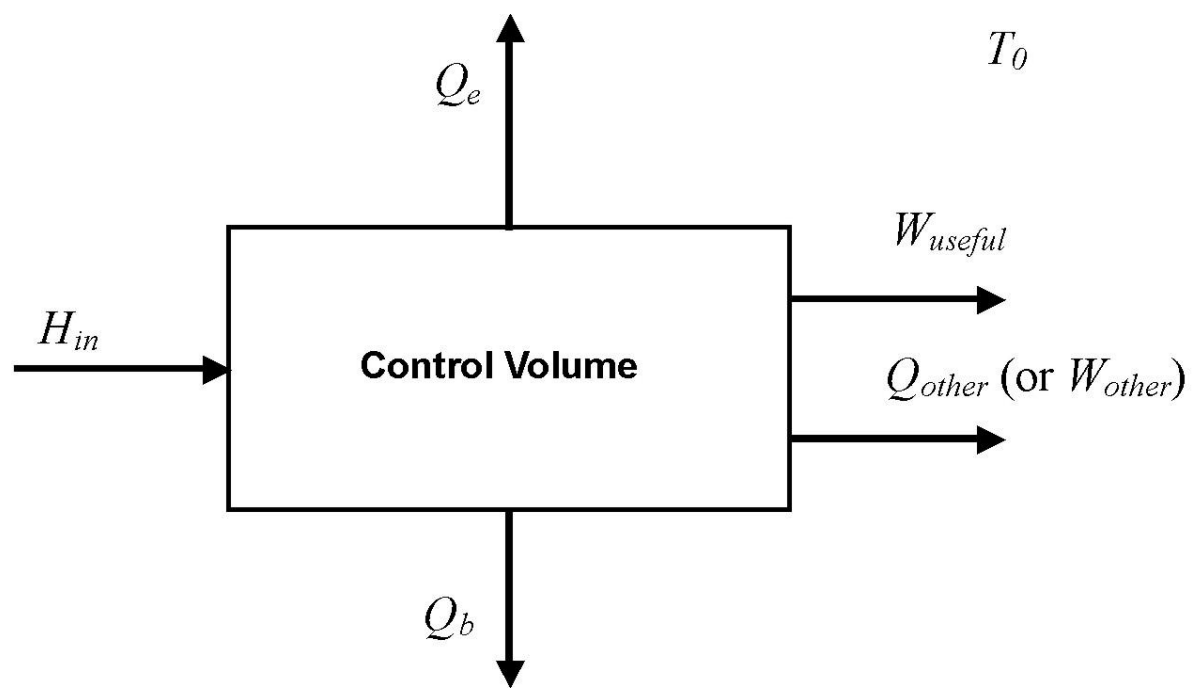

This is not a very helpful expression, as many of the energy output streams will be in the form of 'waste heat'. Excluding waste streams, then energy efficiency may be rewritten in more realistic terms as:

$$
\eta=\left(\mathrm{H}_{\text {out }}\right)_{\text {useful }} / \mathrm{H}_{\text {in }}<1
$$

The First Law was the basis of a techniques developed in the mid-1970s that became known as 'energy analysis' [23]. In order to determine the primary energy inputs needed to produce a given amount of product or service, it is necessary to trace the flow of energy through the relevant industrial system. This involves the entire life-cycle of the product or activity from "cradle-to-grave". The system boundary for energy analysis should strictly encompass the energy resource in the ground (for example, oil in the well or coal at the mine), although this is often taken as the national boundary in practice [10,22,23]. Thus, the sum of all the outputs from this system multiplied by their individual energy requirements must be equal to the sum of inputs multiplied by their individual requirement.

This process consequently implies the identification of feedback loops, such as the indirect, or 'embodied', energy requirements for materials [24] and capital outputs. This procedure is illustrated schematically in Figure 3 [3], which was adapted from one given by Slesser [23]. Different 'levels of regression' may be employed, depending on the extent to which feedback loops are accounted for or the degree of accuracy wanted. There are several different methods of energy analysis; the principal ones being statistical analysis, input-output table analysis and process analysis [23,25]—again illustrated in Figure 3 [3]. The first method is limited by the available statistical data for the whole economy or a particular industry, as well as the level of its disaggregation. Statistical analysis often provides a reasonable estimate of the primary energy cost of products classified by industry. However, it cannot account for indirect energy requirements or distinguish between the different outputs from the same industry [3]. The technique of input-output table analysis, originally developed by economists [24], can also be utilised to determine indirect energy inputs and thereby to provide a much 
Figure 3. Schematic representation of the energy analysis process. Source: Hammond [10]; adapted from Slesser [23].

\section{LEVELS OF REGRESSION -}

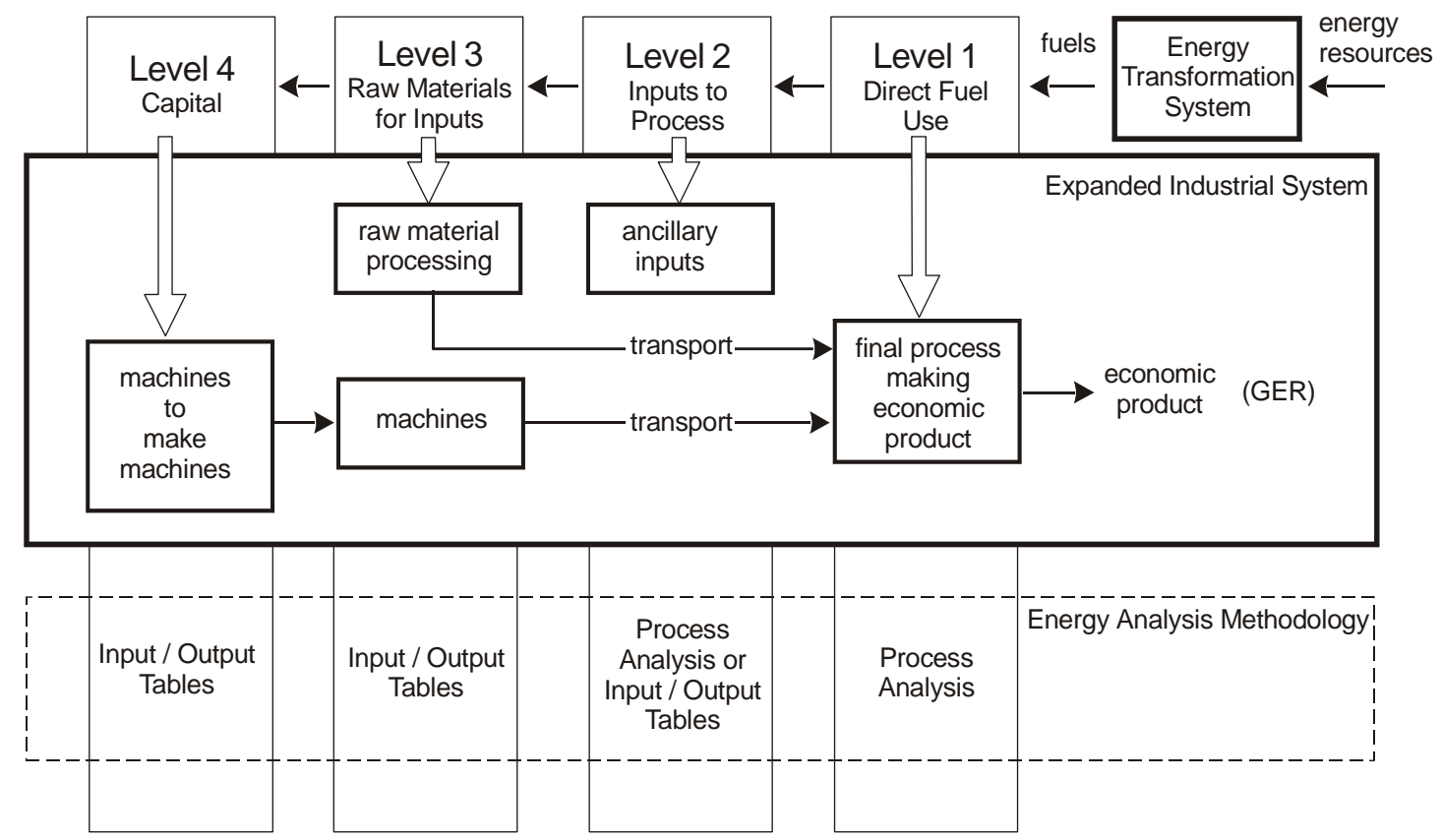

better estimate of 'primary energy' use. This approach is constrained only by the level of disaggregation that is available in national input-output tables [24]. Process energy analysis is the most detailed of the methods, and is usually applied to a particular process or industry. It requires process flow-charting using conventions originally adopted by the International Federation of Institutes of Advanced Studies in 1974-1975 [23,25]. The application domains of these various methods overlap. They can be used to determine the least energy-intensive industrial process from amongst a number of alternative options.

\subsection{The Foundations of Exergy Analysis}

First Law or 'energy' analysis takes no account of the energy source in terms of its thermodynamic quality. It enables energy or heat losses to be estimated, but yields only limited information about the optimal conversion of energy. In contrast, the Second Law of Thermodynamics indicates that, whereas work input into a system can be fully converted to heat and internal energy (via dissipative processes), not all the heat input can be converted into useful work. [This Second Law 'asymmetry' also dictates that, although heat can flow down a temperature gradient unaided, shaft work or an electrical energy input is required in order for heat transfer to take place from a cold to a hot reservoir (as in the case of a heat pump)]. The Second Law therefore suggests the need for the definition of parameters that facilitate the assessment of the maximum amount of work achievable in a given system with different energy sources. 'Exergy' is the available energy for conversion from a donating source (or reservoir) with a reference to a specified datum, usually the ambient environmental conditions (typically 1 bar and $5-25^{\circ} \mathrm{C}$ ). This quantity or its close relatives have been given a variety of names in the literature, 
including availability, available energy, available work and essergy [21]. In a sense it represents the thermodynamic 'quality' of an energy carrier, and that of the waste heat or energy lost in the reject stream. Electricity, for instance, may be regarded as an energy carrier having a high quality, or exergy, because it can undertake work [10]. In contrast, low temperature hot water, although also an energy source, can only be used for heating purposes. This distinction between energy (strictly enthalpy) and exergy is very important when considering a switch, for example, from traditional internal combustion engines to electric, hybrid, or fuel cell vehicles. Thus, Hammond [3,10] has argued that it is important to employ exergy analysis alongside a traditional First Law energy analysis in order to illuminate these issues. It provides a basis for defining an exergy efficiency, and can identify exergetic 'improvement potential' within systems.

Exergy is lost or degraded in every irreversible process or system. Consequently an exergy budget on a control volume can be formulated in an analogous manner to the First Law energy balance, Equation (1), as [10,26]:

$$
\sum \varepsilon_{\text {in }} \mathrm{m}_{\text {in }}-\sum \varepsilon_{\text {out }} \mathrm{m}_{\text {out }}+\sum\left(\mathrm{E}^{\mathrm{Q}}-\mathrm{E}^{\mathrm{W}}\right)-\mathrm{I}=0
$$

where $\mathrm{E}^{\mathrm{Q}}$ and $\mathrm{E}^{\mathrm{W}}$ denote the exergy transfer associated with $\mathrm{Q}$ and $\mathrm{W}$ respectively, $\mathrm{I}$ is the system exergy consumption or irreversibility, and $\varepsilon$ represents the specific exergy. This exergy budget is represented schematically in Figure 4 [10]. Here heat transfer at a constant temperature (say $T_{p}$ ) the 'thermal exergy' is given by [21,26]:

$$
\mathrm{E}^{\mathrm{Q}}=\left(1-\mathrm{T}_{\mathrm{o}} / \mathrm{T}_{\mathrm{p}}\right) \mathrm{Q}
$$

Equation (6) can also be simplified like its First Law equivalent to yield [21]:

$$
\sum \mathrm{E}_{\mathrm{i}, \text { in }}>\sum \mathrm{E}_{\mathrm{j}, \text { out }}
$$

Thus, the exergy loss or irreversibility rate [27] of the system is given by:

$$
\mathrm{I} \equiv \Delta \mathrm{E}_{\text {lost }}=\mathrm{E}_{\mathrm{in}}-\mathrm{E}_{\text {out }}>0
$$

Kline [18] argues that this 'irreversibility', perhaps better denoted by the term exergy 'degradation' or 'destruction' [19], can be interpreted as the dissipated 'available energy' (or exergy) that ends up as random thermal fluctuations of the atoms and molecules in the exit flow of mechanical devices. He illustrates this process by way of examples drawn largely from the sort of rotating fluid machines with which he was most familiar (essentially kinetic energy converters). According to Kline [18] dissipated 'available energy' (or exergy) ends up, in the context of fluid flow, as random thermal fluctuations of the atoms and molecules. This implies that diffusion phenomena can only be understood as an interaction between processes at both the macroscopic and microscopic levels (see also Hammond [19]). In contrast, the detailed mechanisms involved in combustion processes are not well understood. Several studies have investigated the sources of irreversibility, or exergy destruction, resulting from such phenomena. They indicate that between about one quarter and one third of the useful exergy in the fuel $\left(E_{i n}\right)$ is destroyed during the combustion of fossil fuels [10]. Dunbar and Lior [28] identified three hypothetically distinct subprocesses: (i) combined diffusion/fuel oxidation, (ii) internal thermal energy exchange (or heat transfer), and (iii) the mixing process associated with the combustion products. They employed a simplified, 'zonal' computational model, 
which indicated that about three quarters of the exergy degradation was linked to heat conduction. In contrast, chemical reaction was found to be quite efficient; the exergy efficiency of this subprocess was typically $94 \%-97 \%$.

Figure 4. An exergy budget for a simple control volume or unit operation. Source: Hammond [10]; upgraded.

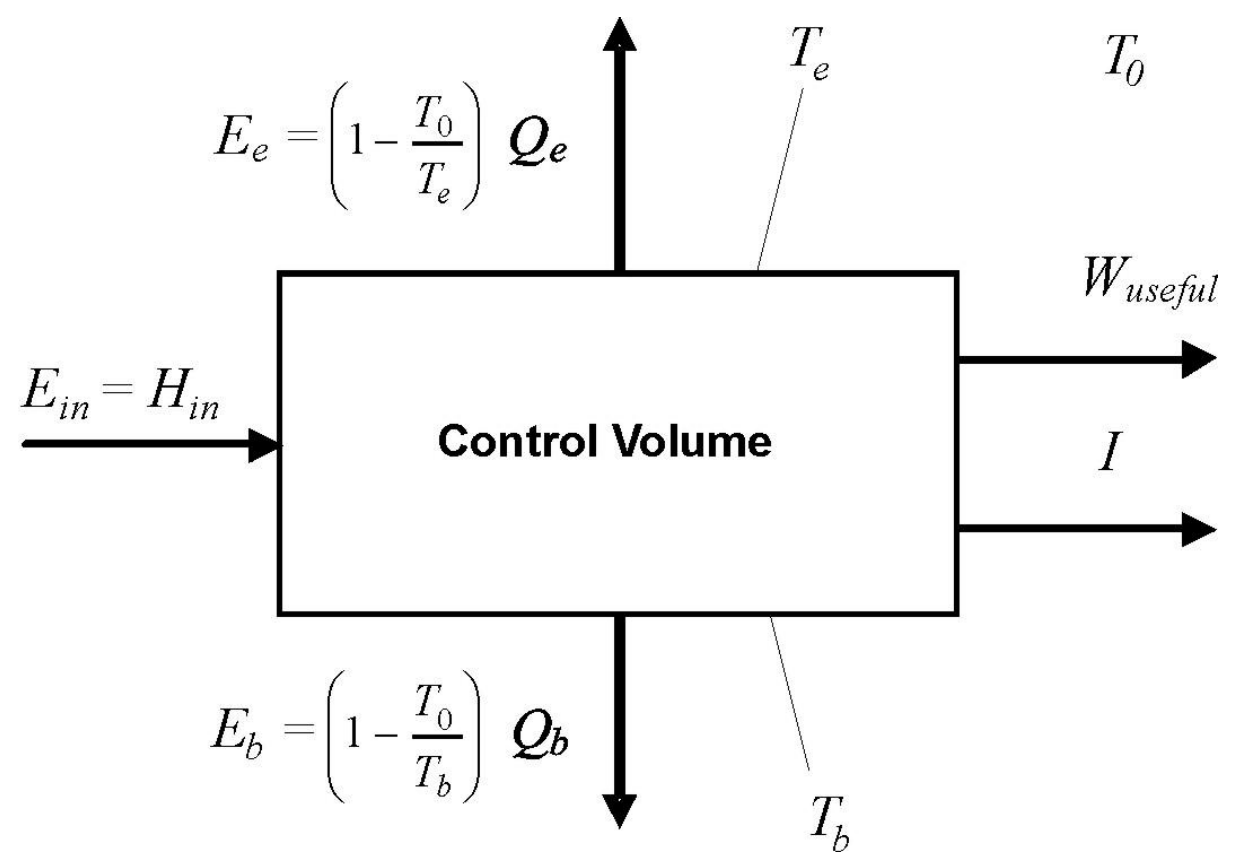

The exergy function itself is another 'extensive' property $[21,26]$, which is defined by reference to a "dead" or equilibrium state (in terms of temperature $\mathrm{T}_{\mathrm{o}}$, pressure $\mathrm{P}_{\mathrm{o}}$, and species component $\mu_{\mathrm{io}}$ ):

$$
\mathrm{E}=\left(\mathrm{H}-\mathrm{H}_{\mathrm{o}}\right)-\mathrm{T}_{\mathrm{o}}\left(\mathrm{S}-\mathrm{S}_{\mathrm{o}}\right)+\sum_{\mathrm{i}} \mathrm{N}_{\mathrm{i}}\left(\mu_{\mathrm{i}}-\mu_{\mathrm{io}}\right)
$$

where $\mathrm{S}$ denotes Clausius entropy and $\mathrm{N}_{\mathrm{i}}$ is the number of moles of species i. Variations in species, or matter, concentration are therefore reflected in the last term on the right hand side. This is where material exchange appears in the thermodynamic domain. Hence, matter does not physically mirror the way in which energy transfer takes place. Such changes in species concentration are not usually significant in problems related to the macro-scale analysis of energy systems. Consequently, a truncated mathematical expression can be used to calculate 'physical' or 'thermomechanical' exergy states:

$$
\mathrm{E}=\left(\mathrm{H}-\mathrm{H}_{\mathrm{o}}\right)-\mathrm{T}_{\mathrm{o}}\left(\mathrm{S}-\mathrm{S}_{\mathrm{o}}\right)
$$

The choice of the reference state has been the subject of some divergence of opinion in the literature. Many use the standard temperature and pressure $\left(\mathrm{T}_{\mathrm{o}}=298 \mathrm{~K}\left(25^{\circ} \mathrm{C}\right)\right.$ and $\left.\mathrm{P}_{\mathrm{o}}=1 \mathrm{~atm}\right)$, whereas Wall [29] adopted $15^{\circ} \mathrm{C}$ as the datum for his country study of Sweden. Nevertheless, a more common basis for heat load calculations in mainland Britain is to assume a winter outside design temperature of about $-1{ }^{\circ} \mathrm{C}$. This was the reference condition adopted by Hammond and Stapleton [21] for their exergy analysis of the UK energy system. It is the same as the "dead state" temperature adopted by Reistad [30] for exergy analysis of space heating in the USA. 


\subsection{The Exergy Method in Practice}

An exergy efficiency, $\psi$, can be defined in much the same way as its energy counterpart [21]:

$$
\psi=\mathrm{E}_{\text {out }} / \mathrm{E}_{\text {in }}=1-\mathrm{I} / \mathrm{E}_{\text {in }}<1
$$

It should be noted that this expression is strictly analogous to Equation (4), rather than the practical First Law (energy) efficiency defined by Equation (5). Comparison with the former equation indicates that, in any real world system (which is irreversible) exergy is degraded and the exergy efficiency is consequently less than unity. Van Gool [27] has noted that the maximum improvement in the exergy efficiency for a process or system is obviously achieved when $\Delta \mathrm{E}_{\text {lost }}$ is minimised; see Equation (9). Consequently, he suggested that it is useful to employ the concept of an exergetic 'improvement potential', IP, when analysing different processes or sectors of the economy. It is given by [27]:

$$
\mathrm{IP}=(1-\psi)\left(\mathrm{E}_{\mathrm{in}}-\mathrm{E}_{\text {out }}\right)
$$

This expression was recently used, for example, by Hammond and Stapleton [21] to evaluate the improvement potential within critical elements of the UK economy.

Now, it was suggested above that exergy analysis provides an indication of the thermodynamic quality of an energy carrier. This was formally defined by van Gool [31] as the ratio of exergy to enthalpy in the flow:

$$
\Theta \equiv \frac{E}{H}
$$

Now, for electricity: $\Theta=1$ and for process heat: $\Theta=\left(1-\frac{T_{0}}{T_{p}}\right)$ (the derivation of which is explained by Hammond and Stapleton [21]; Reistad [30]; Rosen and Dincer [26]). Electricity is essentially a 'capital' resource that is normally generated in advanced, industrialised countries using either depleting fossil or nuclear fuels (see, for example, Hammond [32]). These latter sources may be contrasted with the renewable (or 'income') energy sources, such as solar energy and tidal, wave and wind power. In contrast to electricity (a high quality energy carrier with $\Theta=1$ as indicated above), low temperature hot water $(\Theta \approx 0.2)$ can only be used for heating purposes. Hammond [10,33] recently devised a graphical representation of the variation in van Gool's thermodynamic quality $(\Theta)$ with the process temperature ratio $\left(\mathrm{T}_{\mathrm{p}} / \mathrm{T}_{0}\right)$ : see Figure 5. This was produced using the environmental datum temperature adopted by Hammond and Stapleton [21] for their energy analysis of the $\mathrm{UK}:-1{ }^{\circ} \mathrm{C}$ (or $\mathrm{T}_{0}=272 \mathrm{~K}$ ). They indicated that the exergy efficiency of various domestic heating appliances was quite sensitive to the choice of this reference temperature, when the process temperature is close to the selected environmental datum. However, both the exergy efficiency $(\Psi)$ and the thermodynamic quality $(\Theta)$ are insensitive when plotted against the process temperature ratio; as depicted by Hammond [10] in Figure 5. Here a very wide variation in $\mathrm{T}_{\mathrm{p}} / \mathrm{T}_{0}$ is displayed, and various heat sources are shown for comparison purposes. The associated process temperatures span the range from liquefied natural gas (LNG) at about $-50^{\circ} \mathrm{C}$ to the optical temperature of our Sun at around $+5,500{ }^{\circ} \mathrm{C}$. 
Figure 5. Temperature dependence of thermodynamic quality. Source: Hammond [10]; with a minor correction.

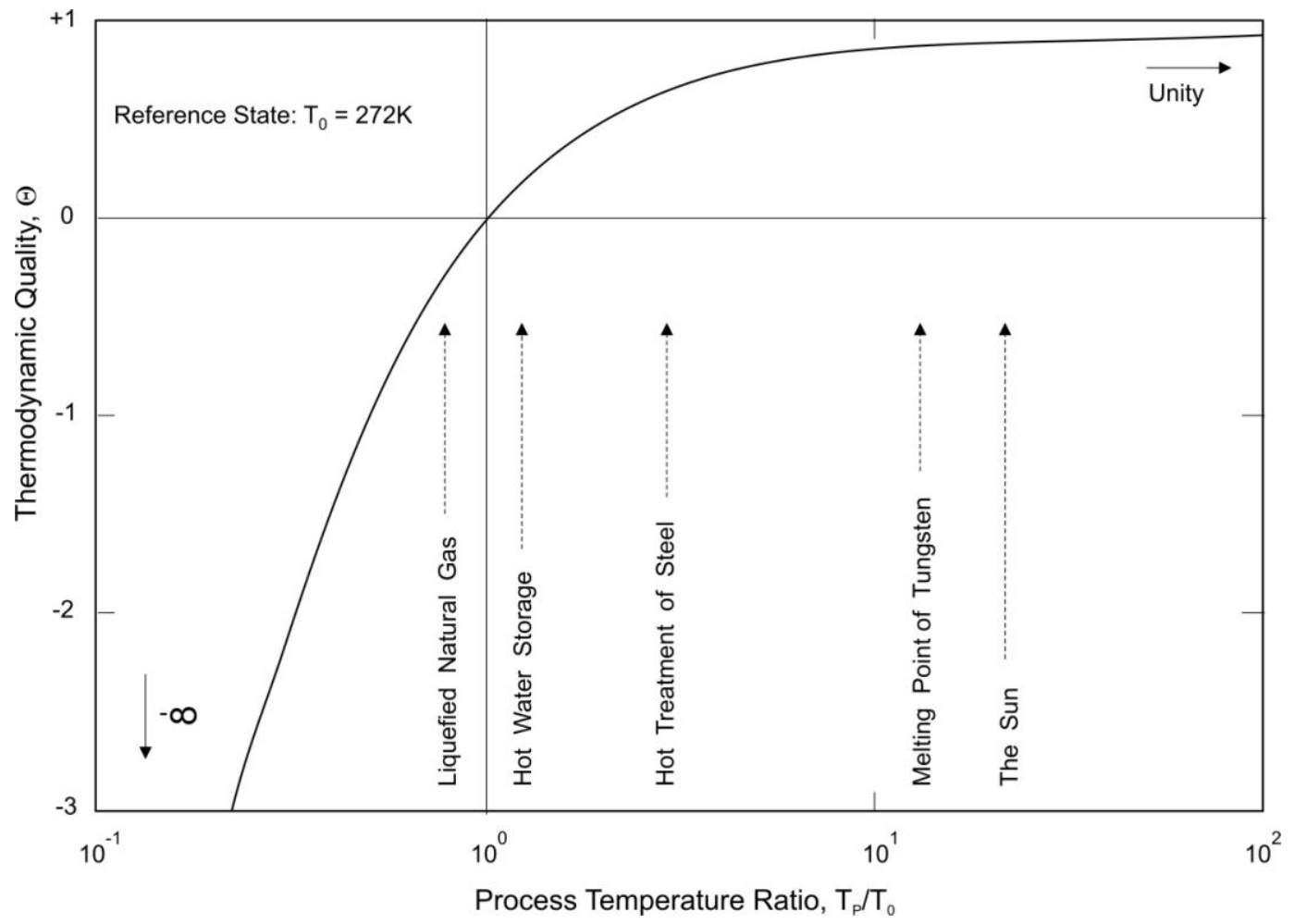

The use of the exergy method of analysis has grown rapidly since the mid-1970s, particularly for optimising individual energy conversion systems and process plant. Van Gool [34] used the example of a gas boiler plant for space heating, which is normally regarded as having quite a high energy efficiency, but is found to have a very low exergy efficiency. Another example is the identification of the true nature of losses in power plant. The major 'energy' losses arise in the condenser, whereas 'exergy' losses occur in the steam generator [30]. Losses in the condenser would suggest little prospect of improvement other than by way of a 'bottoming cycle'. However, exergy analysis indicates that the main improvement potential is associated with combustion processes and with heat exchangers. Making improvements at the 'top end' of the cycle will have the 'knock-on' benefit of also giving rise to higher First Law efficiencies [21]. The feasibility of such changes is arguably not as important as a proper comprehension of the thermodynamic processes involved [35].

Large energy losses occur during electricity generation unless used in conjunction with combined heat and power (CHP) systems. Thus, the only ways to improve the efficiency of the 'energy transformation system' significantly, in the absence of new large-scale hydropower sites, is either to restrict the use of electricity to power applications (and not for relatively low-temperature heating) or to adopt a greater proportion of CHP plants. Such schemes have an overall First Law efficiency $(\eta)$ of some 80 per cent in contrast with the best recuperative CCGT plant of 59-61 per cent. The results of a recent Canadian parametric study by Bilgen [36] of a CHP cycle (or what the North Americans term a 'cogeneration' plant) are illustrated schematically in Figure 6 [10]. This study examined a nominal 22 
Figure 6. Thermodynamic performance of combined heat and power plant. Source: Hammond [10]; adapted from Bilgen [36].

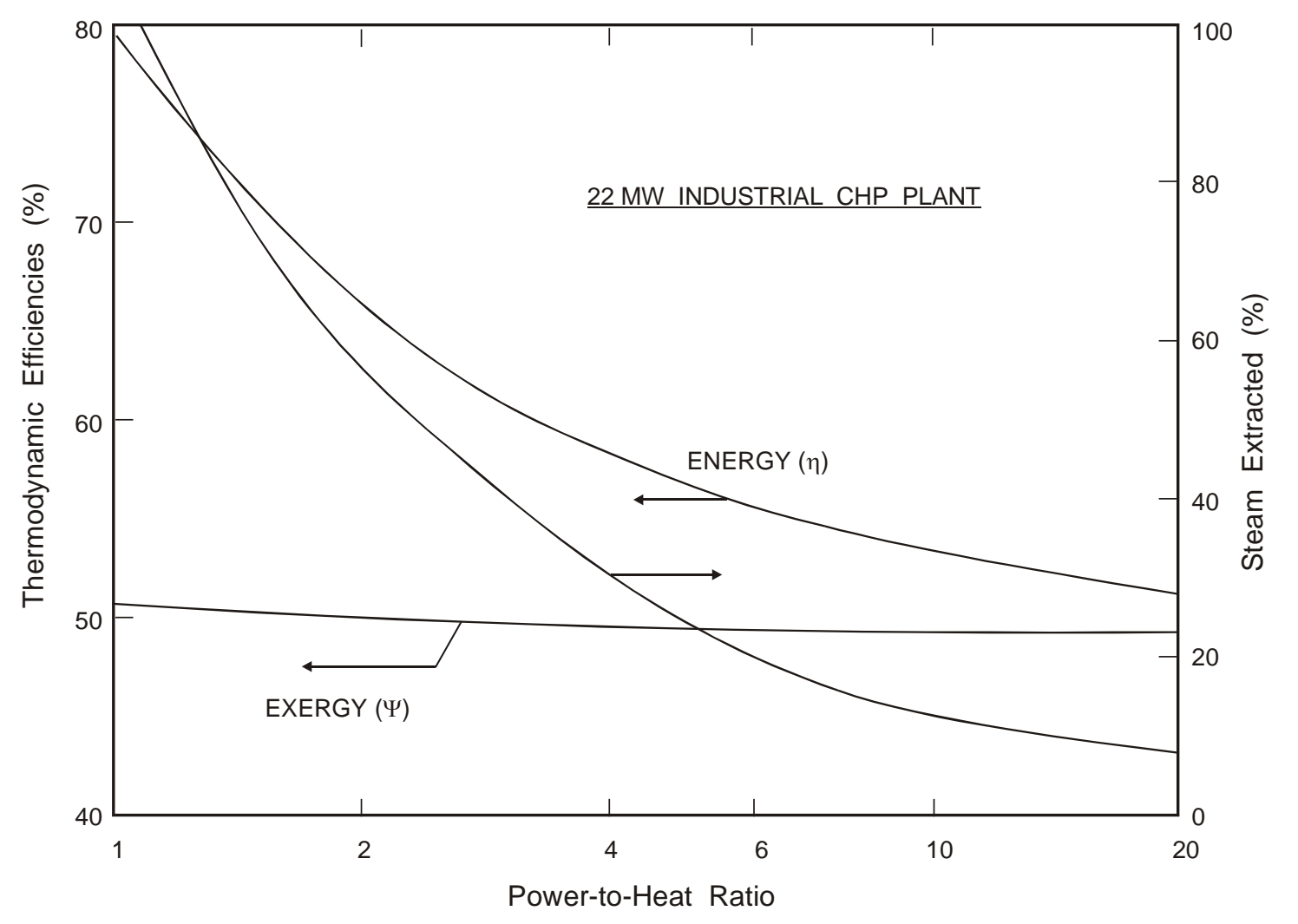

MW industrial turbine set manufactured in the USA, which typically operates on a power-to-heat ratio of 0.92. It can be seen from Figure 6 that the First Law (energy) efficiency falls sharply with power-to heat ratio and the proportion of process steam extracted. In contrast, the exergy efficiency $(\psi)$ is insensitive to these parameters. This is because it reflects the ability to perform work and the efficiency of power generation only. However, CHP plants are obviously desirable on fossil fuel resource productivity grounds. It is therefore evident that this is a situation where exergy analysis on its own is insufficient, and needs to be used in parallel with energy analysis in order to reflect the interrelated constraints imposed by the First and Second Laws [10,35].

\subsection{The Gibbs Free Energy}

In the field of ecology, strictly the branch of the natural sciences that deals with the relation between biological organisms and their physical surrounding, the concept of Gibbs free energy or function $(\mathrm{G})$ is used in preference to exergy [37]. It is defined mathematically as:

$$
\mathrm{G}=\mathrm{H}-\mathrm{TS}
$$

The connection between this thermodynamic property and the physical (or thermomechanical) part of exergy can to seen by way of comparison of this expression with the truncated expression for exergy; Equation (9). Gibbs free energy is again the maximum work that is available from a natural or other system, but it is not determined by reference to the surrounding environmental conditions. The 
dead state temperature is effectively taken to be absolute zero $\left(-273{ }^{\circ} \mathrm{C}\right)$. However, in many cases, it is the change in free energy $(\Delta \mathrm{G})$ that is significant to the problem being considered, and this is nearly the same as the corresponding change in physical exergy $(\Delta \mathrm{E})$ - Hammond [10] noted that they are identical when $\mathrm{T}=\mathrm{T}_{\mathrm{o}}$. Exergy and Gibbs free energy therefore play a similar in thermodynamic analysis; they are simply alternative choices for most practical purposes.

\subsection{Entropy}

Dissipative processes in mechanical systems give rise to 'irreversibilities' (or exergy destruction). If a process or cycle, for example, involves either friction or heat transfer across a finite temperature difference, then they cannot be considered reversible. Chemical processes that involve a spontaneous change of material structure, density or phase are also irreversible. The 'energetic' or Clausius entropy is a Second Law extensive property that is a measure of such irreversibilities, and is defined as:

$$
S_{2}-S_{1}=\int_{1}^{2} \frac{d Q_{R}}{T}
$$

It can be seen that entropy is the integral quantity measured from some starting condition (1). Entropy rises whenever irreversible processes take place; as in all real world systems. It can be contrasted with nature of the First Law 'enthalpy' described in Section 4.1 above [22,38]. In order to determine entropy changes, there is a complicated experiment implied by Equation (16), as well as the need for mathematical manipulation. The experimental measurements needed to determine the heat exchange would need to be carried out under the ideal conditions of reversibility; a requirement that is almost impossible to satisfy. In addition, the numerical manipulation of the results of such an experiment would require relatively advanced mathematics (that is, integral calculus), and not the sort of elementary arithmetic needed to evaluate First Law enthalpy. Spalding and Cole [22] note that there is no 'physical picture' of entropy and that it is not obvious that it has an important role, for example, in engineering calculations. Furthermore, Hammond [13] and Hammond and Stapleton [21] have argued that enthalpy can be readily seen to represent the 'quantity' of energy required for the provision of a product or service, and that exergy reflects its corresponding 'quality'. Exergy is thus a more easily understood thermodynamic property than is entropy to represent system irreversibilities [38]. Its value falls (or degrades) in real world systems; in contrast to that for entropy.

It is apparent from the discussion above that the concept of entropy is not an easy concept to grasp, although it has been so widely used and abused [19,38]. Many analogous properties have been proposed. In addition to the energetic or Clausius entropy, Kline [18] identified five microscopic 'entropies' (including Gibbs' statistical entropy), two information functions (Shannon's and Brillouin's so-called 'entropies'), and what he amusingly denoted as the 'vulgar' entropy (see Hammond [19]). Kline [21] interprets Gibbs' statistical entropy as a useful measure of the "spreadoutness" of random molecular fluctuations amongst various microstates within the constraints of the physical boundaries of a system. However, he criticises the attribution of the term 'entropy' to information functions as an error of typology; saying it is like equating "apples with oranges". These are not unique criticisms, and Kline points to earlier reservations by the likes of Denbigh, Fast, Pierce, and Popper [18,19]. 


\section{From Classical to Ecological Economics}

\subsection{The Limits to Micro-Economic Analysis}

In the neoclassical study of economics the system studied is founded on actions of, and interactions amongst, individual producers or consumers ('agents'). This is a system that may well be sub-optimal in natural resource and environmental terms [25]. The transactions between these agents and the rest of the world are economically described in terms of the quantities and prices of (broadly defined) commodities that are exchanged. Prices in this classic economic model are supposed to reflect the 'value' that society places on an economic good. Thus, economics is claimed to be a 'normative' discipline: it suggests the optimal course action to be taken in the allocation of resources. For the price of commodities to give information that will lead to an efficient use of resources, it is necessary to assume that the prices are determined in complete and perfectly competitive markets. Obviously there may be imperfections in the structure of the market; for example, social costs (notably environmental externalities) may not be transacted and therefore remain unpriced. There are also likely to be uncertainties about the future, restricted information about technological possibilities and time-lags, all of which might cause prices to deviate from those which would lead to optimal investment decisions $[3,9,25]$.

\subsection{From Environmental to Ecological Economics}

Over the past twenty years or so environmental economics has moved from being a fringe activity to become one of the most active fields of economic research. It is now a major, even dominating, influence within significant areas of policy debate, including global issues such as climate change and biodiversity loss. Mainstream environmental economics is primarily influenced by the neoclassical paradigm in the ways in which it formulates and analyses the two key issues of concern: the valuation of ecological assets and the design of policy instruments to manage those assets [4]. These are brought together in the contemporary study of sustainable development. Thus, environmental economics is essentially a branch of applied welfare economics. In some respects environmental economics represents a rather extreme interpretation of the neoclassical economic paradigm, with its belief in the possibility of extending individual valuations to all sorts of non-marketed 'commodities'. Here environmental problems are essentially defined as flowing from 'market failures', and incentive-based policy instruments are advocated to correct such failures with efficacy.

In the neoclassical view, environmental problems are just one species of externality that should be costed at the price which an efficient market would impute to them: they would not exist if markets were complete and in equilibrium. This seems to fail to grasp the existence of real environmental problems independent of their specification in an economic model [4]. Nevertheless, it might be a reason for adopting one of the alternative accounts of what may be called environmentally-embedded sustainability in order to clearly define the nature of such problems.

In many, perhaps most, of the cases which are of interest to environmental economists, there are no observable or even imputable prices of any sort to use in such valuations. The various methods that have been proposed for valuing external costs and benefits are all open to criticism (see, for example, 
Hammond and Winnett [3]). Choice of different valuation methods can lead to a wide variation in the supposed costs and benefits. This valuation process is uncertain and potentially controversial, often relying on the determination of shadow prices. In the extreme, they result in methods for valuing human life and well-being that are quite at odds with that perceived by the individual or by society as a whole [3]. Similar difficulties arise in valuing other elements of the biosphere. One widely adopted procedure is to invoke the so-called 'contingent valuation method'; eliciting prices by questioning people about their "Willingness to Pay" (WTP) for ecological benefits or to accept environmental losses. However, the answers given in contingent valuation surveys could simply represent an attempt by respondents to formulate a response based on prices that people know in their everyday economic lives [4], rather than a properly formulated reaction based on the nature of environmental assets.

Partly owing to its somewhat extravagant faith in the neoclassical paradigm, and partly because of the necessary interface between environmental economics and the natural sciences, mainstream environmental economics has had its critics. Some of this criticism is simply misplaced (for example, that it cannot account properly for the life-cycle of products), and is easily rebutted by any well-trained neoclassical economist (see, for example, Winnett [4]). But some are fundamental. This is especially true of those critics who challenge the foundations of neoclassical approaches to the environment. The same goes for those proposals for the use alternative accounts of sustainability based on physical or natural processes intrinsic to the biosphere, such as energy usage [6,39] or biological resilience [40]. Such accounts often aspire to create an entirely new form of economics based, for example, on a redefinition of the concept of scarcity or value.

Dissatisfaction amongst scholars with the ecological limitations of environmental economics has led to the development of the emerging transdisciplinary field of 'ecological economics'. At the forefront of this activity have been individuals like Robert U. Ayres, Jeroen C.J.M. van der Bergh, Cutler J. Cleveland, Robert Costanza, Herman Daly, Nicholas Georgescu-Roegen, John M. Gowdy, Charles Hall, Kozo Mayumi, Howard T. Odum, R. Kerry Turner, and Matthias Ruth: to name but a representative few. They come from a wide range of disciplines, including various branches of biology, ecology, economics, engineering, and geography. Some, like eminent ecologist and systems analyst H.T. Odum [41,42], laid the foundations for more than one new area of ecologically-related study. Odum was engaged in the instigation of two interdisciplinary fields: 'ecological economics' and 'ecological engineering' [42]. Interestingly in the present context, he was fully engaged with others in the discourse about Second Law concepts in the 1980s. He attended a Gordon Research Conference in New England around 1984 [43], during which he gave one of the preliminary talks; along with Georgescu-Roegen and the distinguished geologist M. King Hubbert. Odum asserted that at that time [43] thermodynamicists were intent on taking what he regarded as a wrong direction in favour of exergy analysis to evaluate the qualitative features of energy systems. He later devised his own method for analysing energy systems, both physical and biological, known as EMERGY analysis [42]. The heterodox nature of field can be judged by the content of the journal titled 'Ecological Economics' [sponsored by the International Society for Ecological Economics]. It sets out its domain of study as being "concerned with extending and integrating the study and management of 'nature's household' (ecology) and 'humankind's household' (economics)." The editors argue that this integration is necessary "because conceptual and professional isolation have led to economic and environmental 
policies which are mutually destructive rather than reinforcing in the long term." The journal aims to be "transdisciplinary in spirit and methodologically open".

\subsection{Sustainability and Economic Thought}

The concept of 'sustainability' is regarded by many economists (see, for example, Winnett [4]) as a highly debatable notion. Its status within neoclassical-oriented environmental economics is not entirely clear: it is essentially a side-condition, rather than being intrinsic to the logic of the model. The core of the concept is that some measure of welfare; often expressed in terms of maintaining an appropriate aggregate capital stock. Welfare is ultimately dependent on the return to stock. The capital stock is very broadly defined, to include natural resource and environmental assets, alongside physical, human, and even social capital [3]. It should be noted that this framework is very widely used, even by those who are dismissive of neoclassical-oriented environmental economics. Indeed, one of the common (but mistaken) criticisms of this branch of economics is that it does not use a comprehensive enough definition of capital. This should to be distinguished from the argument that the market-based values utilised in aggregation are inappropriate [3].

Many of the mainstream accounts of sustainability-as-maintaining-aggregate-capital strengthen the criterion by requiring some individual components of the aggregate to be maintained as well. This is on the grounds that the weaker criterion overestimates the possibilities of substitution within the economy, though others are more sanguine. But introducing it as an assumption does raise questions about the coherence of the neoclassical model of sustainability, which do not seem to be very clearly appreciated. Economists are fond of arguing that prices are uniquely efficient descriptors and aggregators. A little reflection will show that it implies that prices are not the efficient aggregators fundamental to the neoclassical paradigm.

\section{Early Attempts to Link Thermodynamics and Economics}

The development of First Law 'energy analysis' in the 1970s (see Section 4.1 above) led to a great deal of interdisciplinary debate in the literature over the link between energy and value, involving both physical scientists and economists. For example, Costanza [44] utilised the 1967 US, 92-sector, input-output table to calculate the total (process plus embodied) energy requirements for products and services [24]. He took account of solar energy input into the economy that was previously ignored by energy analysts. This resulted in a strong relation between embodied energy, including the energy required to produce labour and government services, and the dollar (\$) value. Costanza suggested that embodied energy, defined in this way, yield accurate indicators of market values that incorporate 'externalities', and might constitute a means for natural resource valuation. He further argued that embodied energy could therefore provide a common denominator in both ecological and economic systems. Other environmental economists have employed thermodynamic ideas to devise alternative accounts of sustainability by analogy with physical or natural processes, such as energy usage (see, for example, Costanza and Daly [39]). Reference was made in Section 1.1 above to the literature that postulates an 'Energy Theory of Value'. Söllner [5] contends that this was largely rejected because choices about (First Law) energy use do not reflect the full complexity of human behaviour and value 
judgements. Ideas of this type have also been criticised by Georgescu-Roegen [45,46] and Mirowski [47], with the latter viewing the proponents as 'neo-energeticists'. The former dissociated himself from proposed links between embodied energy and economic value (as suggested by Costanza [44] and others) largely because it takes no account of Second Law degradation. Mirowski [47] observed that the neo-energeticists were almost entirely "engineers who have taken it upon themselves to improve the scientific tenor of economics". While not wanting to advocate an 'energy theory of value', the present authors would wish to see a greater interchange between economists and engineers in order to stimulate mutual understanding across the economy-environment system boundary.

Chemists and chemical process engineers have long been concerned with the need to achieve optimal performance from heat exchange and process plant, including minimising their environmental impact. The distinguished Dutch physical chemist Willem van Gool (1926-1998), for example, recognised the significance that the financial costs of process plant play in equipment selection (see the memorial review by Hammond [33]). Van Gool studied, with various collaborators, the trade-off between energy use and financial costs of various processes, or 'unit operations' $[48,49]$. This initially involved evaluating the minimum product (direct or 'process', plus the indirect or 'embodied') energy required for different types of process equipment. He recognised [48] that the embodied energy is not really recoverable from the equipment, except via materials substitution. However, a typical trade-off between process and embodied energy is illustrated in Figure 7. Here the process energy curve is similar to that later derived by Cleveland and Ruth [50], although with its axes transposed, to represent the trade-off between energy and materials inputs per unit of outputs. The more significant finding by van Gool was that embodied energy is a fundamental or intrinsic part of the total energy needed to construct and operate process equipment (see Section 4.2). He went on [34,48] to study the trade-off

Figure 7. Product (process + embodied) energy consumption associated with unit operations. Source: Hammond [33]; adapted from van Gool [49].

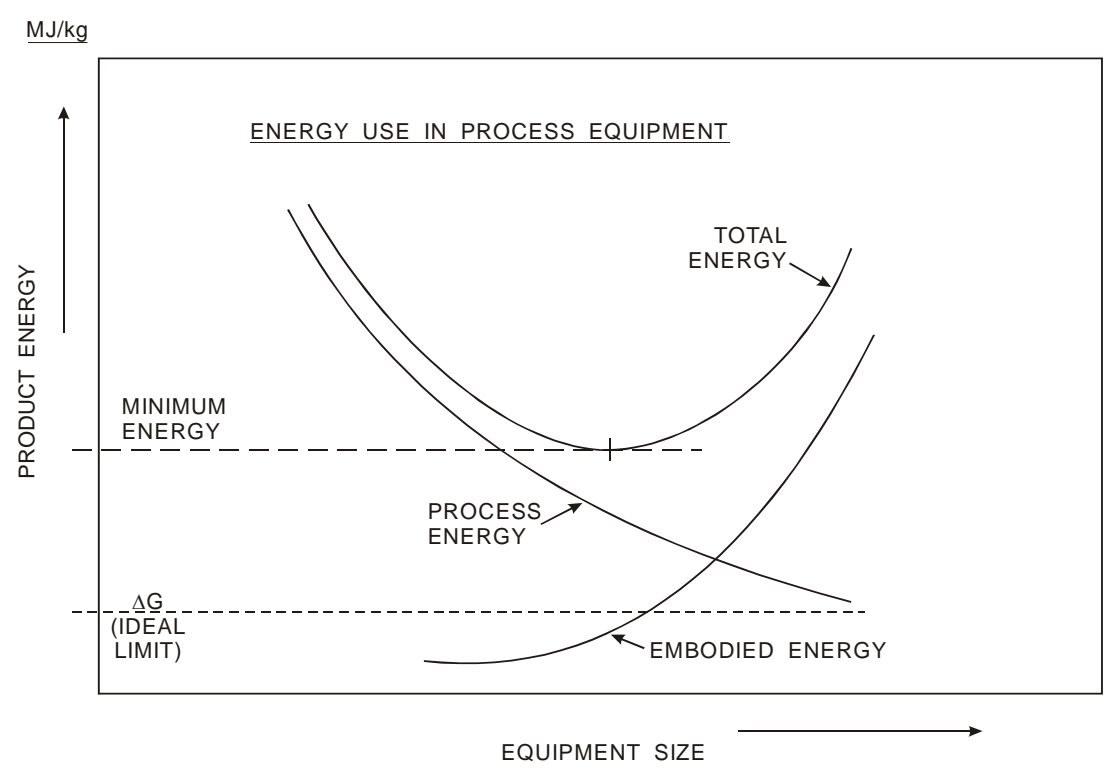


Figure 8. Trade-off between product energy use and financial costs associated with unit operations. Source: Hammond [33]; adapted from van Gool [34].

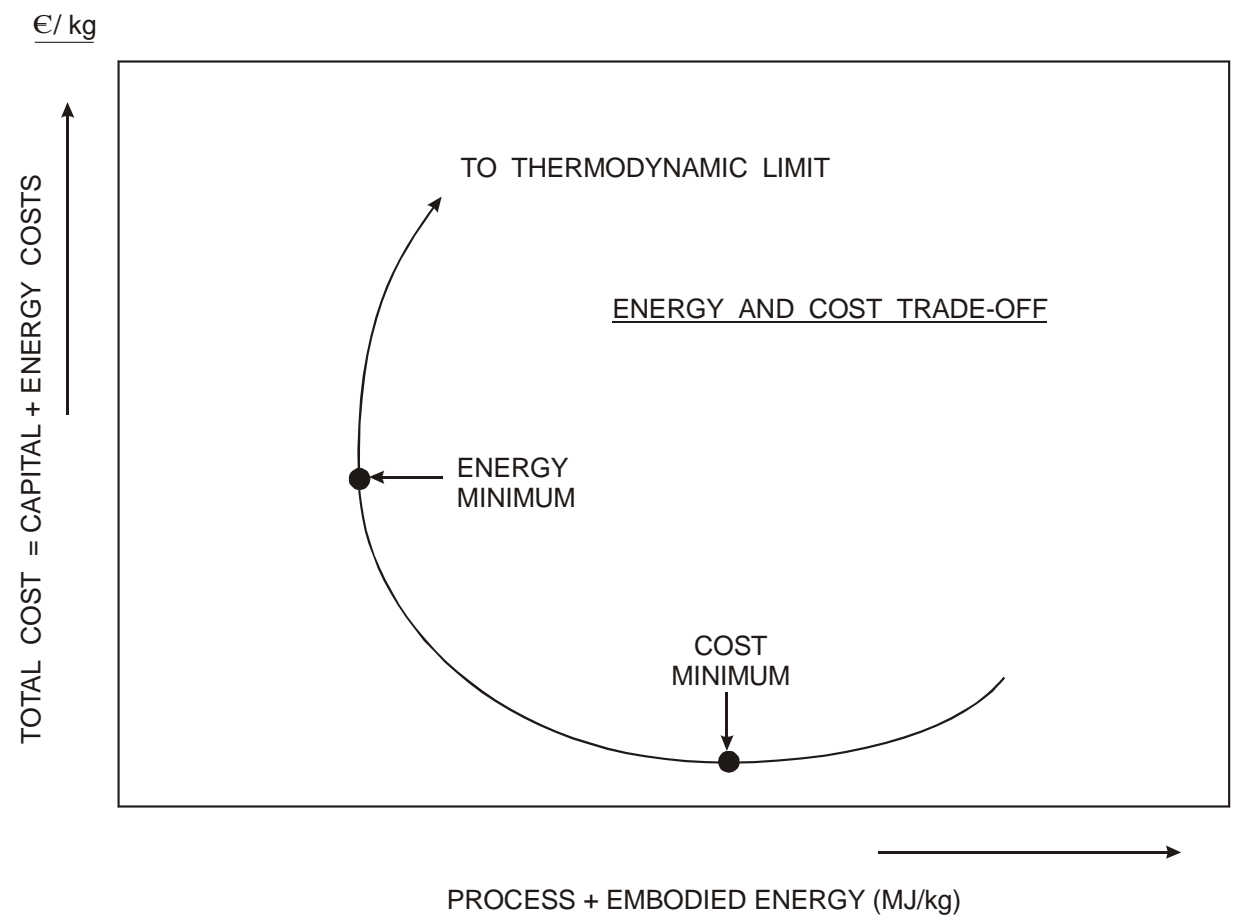

between the total energy requirements for investment in process plant and the consequent lifetime financial costs. These are shown in Figure 8, where minima associated with the total energy requirement and financial costs are depicted.

van Gool's later work highlighted the insights that could be provided by exergy analysis in terms of determining the theoretical energy saving potential of a product or activity (see Hammond [33]). However, there is a need to distinguish between thermodynamic optimal plant or product design and what can be feasibly achieved in practice $[3,35]$. This is illustrated schematically in Figure 9 (adapted from Jaffe and Stavins [51]), which depicts the economic and technical barriers (as well as the thermodynamic limits) that must be faced in securing energy efficiency savings in practice. Roughly this implies that, although the thermodynamic (or exergetic) improvement potential is around $80 \%$, only about $50 \%$ of energy currently used could be saved by technical means and, when economic barriers are taken into account, this reduces to perhaps some $30 \%$. Nevertheless, this still implies that there is very significant scope for innovation in energy efficiency over the longer-term $[3,35]$ within the sort of trade-offs and constraints reflected in Figure 8.

A brave attempt to investigate interdisciplinary approaches to long-term energy problems and the employment of thermodynamic concepts was made in a workshop organised under the auspices of the Dutch Energy Study Centre in the mid-1980s (see van Gool and Bruggink [52]). Here similarities and differences between the physical sciences and economics were explicitly investigated, and many enduring insights obtained. This attempt at interdisciplinary discourse has not received universal acclaim, and Mirowski [47] protested that many of the contributors were advocates of the identity between energy and economic value: the 'neo-energeticists'. Nevertheless, it is interesting to see that in his commentary van Gool noted that there were nearly as many interpretations of the theme as participants in the workshop. 
Figure 9. The energy efficiency gap between theory and practice. Source: Hammond [35]; adapted from Jaffe and Stavins [51].

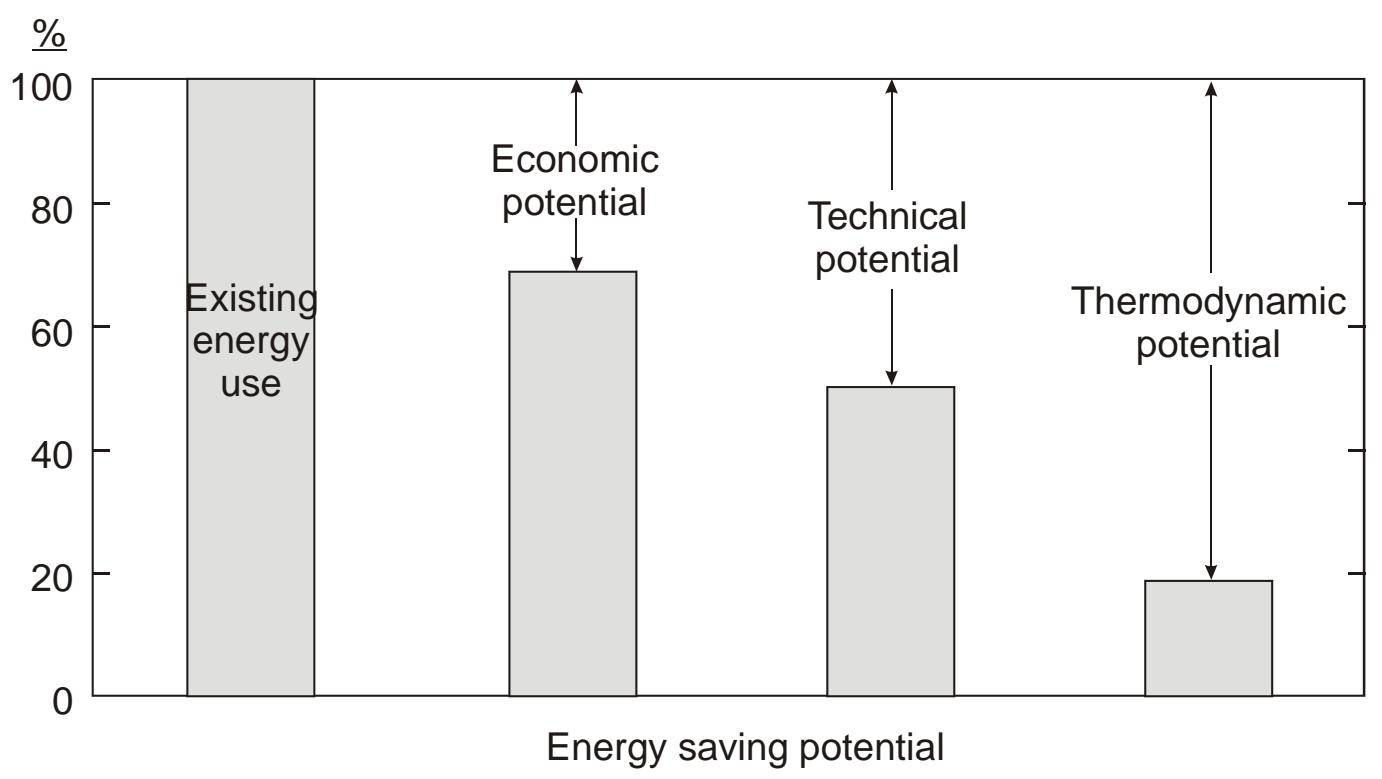

\section{Georgescu-Roegen, ‘The Entropy Law' and Ecological Economics}

\subsection{Nicholas Georgescu-Roegen (1906-1994)}

Borne in Rumania into modest family circumstances just prior to the First World War, Nicholas Georgescu-Roegen excelled in mathematics and statistics. His university education included periods at the University of Bucharest, and had a two-year fellowship at the Sorbonne's Institut de Statistique in Paris (working with Emile Borel and Georges Darmois), extended for a further two years of postgraduate study with Karl Pearson in London (for a fuller description of Georgescu-Roegen's life and work, see Mayumi and Gowdy [53]). Georgescu-Roegen held an appointment as Professor of Statistics at the University of Bucharest from 1932-1946, during which time he gained a Rockefeller Fellowship at Harvard (1934-1937), where he came under the influence of the economists Joseph Schumpeter and Wassily Leontief, amongst others. He played a role back in Rumania on the National Council of the Peasant Party, and also held the post of Secretary-General of the Rumanian Armistice Commission during 1944-1945. Georgescu-Roegen and his wife (Otilia) escaped from the turmoil of the post-Second World War Communist takeover of Rumania stowed abroad a foreign freighter, eventually returning to Harvard in 1948 via Turkey and France. Vanderbilt University (in Nashville, Tennessee) subsequently offered him a post within their Faculty of Economics in 1949, where he remained for the rest of his career. Georgescu-Roegen became the Distinguished Professor of Economics in 1967, and formally retired from the faculty in 1976. His academic studies can be divided into contributions to the 'normal' and 'revolutionary' economic sciences [54]. In the former category can be listed agrarian economics, consumer theory, and Leontief-type linear activity models [55]. They were all underpinned by Georgescu-Roegen's mathematical strength in neoclassical economics. But it is his revolutionary or unorthodox work on thermodynamic insights for economic theory, leading to what he later called 'bioeconomics', that is of interest in the present context. 
There have been many published tributes to Georgescu-Roegen and his work before and after his death; see, for example, Mirowski [47], Daly [54], Maneschi and Zamagni [55] and Mayumi and Gowdy [53]. He was elected a Distinguished Fellow of the American Economics Association [55], but resigned in later life in a protest over the publication of material that Georgescu-Roegen regarded as of questionable merit, as well as perceived "cavalier treatment by some prominent economists" [53]. Although the likes of Nobel economics laureate Paul A. Samuelson have given fulsome praise to his many contributions (writing, for example, the 'Foreword' to a collection of essays in Georgescu-Roegen's honour edited by Mayumi and Gowdy [53]), his more revolutionary ideas have not permeated the mainstream economics literature. His magnum opus, "The Entropy Law and the Economic Process' [6], was viewed by Mirowski [47] as "one of the great unsung classics of economics in the twentieth century". Maneschi and Zamagni observe that Georgescu-Roegen's attempts to convert neoclassical economists to his bioeconomic ideas were not helped by his tendency to refer to them as 'standard' economists.

\subsection{Real World Economics and Thermodynamics}

The neoclassical model of the economic process postulates an isolated circular flow of money from firms to households (see also Section 5.1 above). Daly [54] argues that, although this model has its uses for analysing monetary exchanges, it fails to account for maintenance and replenishment of resources; 'externalities' as far as the neoclassical paradigm is concerned. In practice, production and consumption rely on a one-way, irreversible, flow of natural resource inputs (from global sources) and outputs of products and wastes (to global sinks) that are therefore extracted and deposited from and to the environment. The interrelation between the economic system and the Earth's biosphere is illustrated in Figure 10; adapted from Cleveland and Ruth [50]. Here the economy is represented as an open sub-system within the larger global ecosystem. [A consistent, but more elaborate, alternative representation of the economy-environment relationship is provided by Söllner [5].] The economic process is sustained by the unidirectional flow of energy and materials that enters the sub-system as low entropy/high exergy inputs, which are then degraded via system irreversibilities, and leave as high entropy/low exergy outputs: low grade waste heat and waste materials. Cleveland and Ruth [50] view the Earth's biosphere as being principally a 'closed' system, whereas the natural environment on which all species depend is actually driven by solar energy inputs; the principal 'income' energy source mentioned in Section 3 above. Consequently, the planet is an open system in respect to solar energy, but effectively closed in terms of matter. [leveland and Ruth draw a distinction between a closed system (in which energy can cross the boundary, but matter could not) and an isolated one.] ndeed peasant economies depend on extraterrestrial, short-wave solar radiation: an abundant energy source of low entropy or high exergy (see Figure 5). The output of such predominately agricultural societies is typically encapsulated in the form of livestock [54]; such as goats and cattle of various sorts. In contrast, industrialised economies depend on terrestrial resources laid down over geological timescales: depleting fossil fuels and minerals of relatively poor ore grade. Georgescu-Roegen [6] regarded the throughput of the economic sub-system as an 'entropic flow' that is subject to the physical constraints of natural resource depletion, environmental pollution, and consequent disruption 
of the biosphere. He argued that Second Law properties, such as entropy (and, by implication, exergy), more realistically reflect dissipative processes.

The dissipative nature of the entropic process emphasises the essential dissimilarity between space and time, in contrast to much of conventional economics. This treats them as analogous: just as commodities can be labelled according to where they are located-the foundational Arrow-Debreu general-equilibrium model handles time by labels according to the date at which commodities are available. This has consequences for the ways in which economists approach problems such as irreversibility and uncertainty, which obviously have implications for their treatment of ecological problems. The entropy law was regarded by Georgescu-Roegen [6] as the 'taproot' of economic scarcity: an American expression that refers to the main root of a plant or tree, growing downwards, from which the smaller roots spread out. Economic systems are thereby seen as ones in which energy and matter is conserved, whilst entropy increases. The major contribution of ecological economics from the 1970s onwards has been to embrace the interaction of the economic process with the constraints imposed by the natural environment; along the lines of the model depicted in Figure 10. Practitioners continue to argue about the mechanisms involved and methods of analysis, but this basic model has been generally accepted by those who consider themselves to be 'ecological economists'.

Figure 10. A simplified representation of energy and material flows across the biosphere and the economic system. Source: Adapted from Cleveland and Ruth [50].

\section{The Earth's Biosphere}

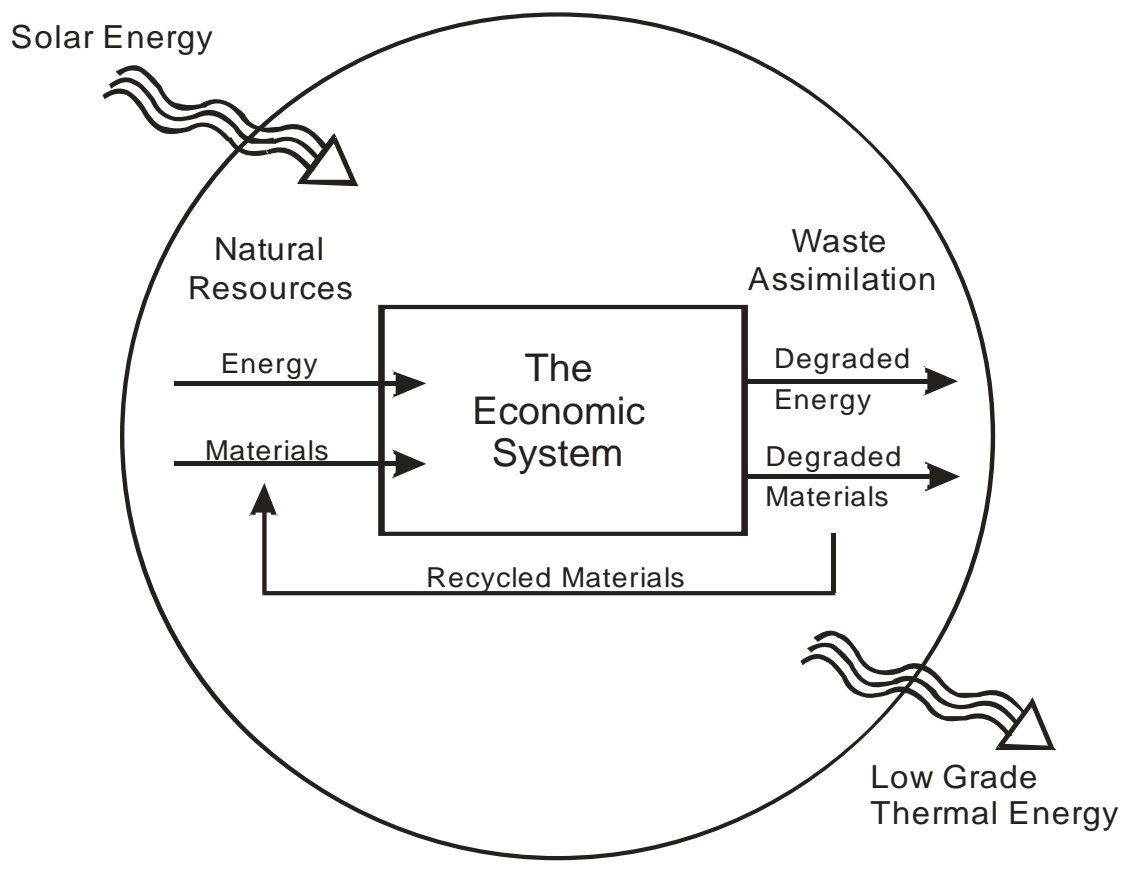

Söllner [5] more recently produced a comprehensive review and critique of the use of thermodynamic ideas in ecological economics. He again drew attention to the insight that energy and related properties can bring to economics and sustainability via the use of analogies and the setting of absolute limits respectively. An important medium-term example of the latter (suggested independently by Slesser [23] and Söllner [5]) is the dominant use and finite nature of fossil fuel 
resources. But there is no direct link between thermodynamic properties and the characteristics of economic systems. The former cannot explain the latter, let alone forecast the future paths of complex economies. Söllner's review [5] was influential in terms of the evolution of the first author's view of the use of thermodynamic concepts outside the realm of energy systems [10], and subsequently on the interdisciplinary discourse of Hammond and Winnett [3] over the application of these concepts in the field of environmental appraisal and valuation.

\subsection{The Appropriateness of Second Law Quantities}

A debate has recently erupted in the literature about the choice of Second Law properties for use in ecological economics; see, for example, Gillett [56] and Lozada [57]. In the context of the findings of the present work, this must be seen as something of a futile exercise. Given that it has been argued here that the application of thermodynamic ideas in the economic domain only amount to a rather loose analogy or metaphor, the precise choice of thermodynamic quantities that are required to reflect the irreversibilities in economics is of only marginal concern. Nevertheless, the debate between the proponents of entropy or exergy as appropriate Second Law properties is likely to persist in the field of ecological economics. Gillett [56] argues in favour of the use of Gibbs free energy; see Section 4.4 above. He suggests that concern about entropy accumulating in the biosphere (see Figure 10) is unwarranted, as waste heat is eventually reradiated out into space in the form of long-wave radiation. In his view, the main use of thermodynamic analysis is for identifying promising technological opportunities, or improvement potential, in common with Hammond [10,33,35] and Hammond and Stapleton [21]. In his response, Lozada [57] expresses a preference for 'entropy maximisation', although he effectively acknowledges that there is a certain interchangeability between exergy, entropy, and free energy [see Equations (10), (11) and (15) here]. The present authors advocate the use of exergy as a measure of thermodynamic quality in physical systems. In part, that is because exergy is an easier Second Law property to measure and understand than, for example, entropy (see Sections 4 above). But they have also argued that both First and Second Law properties (enthalpy and exergy, say) are needed to characterise the quantitative and qualitative thermodynamic consequences of energy systems (see Section 4.3 above). More importantly, Lozada points out that free energy (or, alternatively, exergy) are not directly related to economic value any more than energy is; see Section 6 above.

\section{4. “Matter Matters Too”: A Fourth Law of Thermodynamics?}

A major concern of Georgescu-Roegen [6] was about the incorporation of 'matter' (minerals or materials) into what he viewed as the thermodynamics underpinning the economic system. He asserted that matter underwent similar irreversible processes to that of energy. Indeed, he felt that whenever energy is degraded in order to perform mechanical work, matter had to be consumed by way of 'friction', combustion, and the like [46]. Thus, he argued that macroscopic matter could be degraded like energy, and therefore required a property analogous to entropy that would reflect these processes. Matter too, he hypothesised, is subject to irrevocable degradation. These considerations led Georgescu-Roegen [46] to formulate a 'Fourth Law of Thermodynamics' [the Third Law, that has not 
been explicitly dealt with here, simply sets physical entropy to be zero at the absolute zero of temperature $(0 \mathrm{~K})]$ : "matter also consists of two states, available (low entropy/high exergy) and unavailable (high entropy/low exergy), and that, just like energy, it degrades continuously and irrevocably from the former to the latter". Here he viewed matter in 'bulk', rather than in microscopic, terms. In regard to a national economy, such as that of the USA, minerals would be dispersed, scattered, or wasted, in the course of production. Some of these waste materials might be recycled, but only subject to limits of a similar type to those imposed by the Second Law of Thermodynamics. Such material degradation would ultimately lead to some finite terrestrial minerals, within an effectively closed system, becoming extremely scarce. In the end, the prospect of increasing 'matter entropy' led him to view mineral availability as being a more important constraint on human development than energy security.

Georgescu-Roegen's Fourth Law of matter entropy represents dubious physics, let alone economics. The dispersion of materials during the production process arises mainly because of various types of machining and processing activities that lead to the generation of 'scrap' (that is potentially recyclable as illustrated schematically in Figure 10). It does not occur principally because of a concentration (or potential) gradient in an analogous manner to heat transfer caused by temperature gradients. Matter therefore behaves like energy only by way of a very loose analogy or parallel. It was indicated in Section 4.2 above that matter has a peripheral role in the definition of exergy [see Equation (10)]: this is where physical material exchange actually appears in the thermodynamic domain. Cleveland and Ruth [50] have reviewed many of the criticisms of the Fourth Law by analysts in both economics and the physical sciences. They note that chemical elements are quite wildly distributed over the Earth's crust and need to be concentrated, or refined, before raw (or 'virgin') materials are turned into useable ones. Likewise, Ayres [58] argued that, in principal, perfect recycling of materials from a waste sink could take place provided there is an adequate energy source of sufficient high exergy, although he acknowledged that, in practice, recycling would be an energy-intensive process [59]. He noted that carbon, oxygen and nitrogen, as well as other elements, are naturally recycled with aid of solar energy in the biosphere. Indeed, Cleveland and Ruth viewed the concentration of dispersed wastes, via recycling, as being unlikely to be any more difficult than extracting raw minerals at the average crustal abundance or oceanic concentration. Perfect recycling is clearly impractical, from both an economic and technological perspective. But significant extraction from wastes is possible provided that there is sufficient energy, of high enough quality, available to do so. Consequently, it can be argued that it is energy (or exergy) and not matter, as Georgescu-Roegen contended, that ultimately provides the resource constraints on production [50,58]. Notwithstanding the weaknesses in the concept of a Fourth Law, Cleveland and Ruth [50] suggest that Georgescu-Roegen's emphasis on the physical limits to materials recycling presaged many recent and useful ideas emanating from the new field of industrial 'ecology' or 'metabolism'.

\section{8. 'Exergoeconomics': the Close Coupling of Exergy and Economic Costs}

The popularity of 'exergy' analysis in Central Europe and North America from the 1980s onwards led to attempts to merge the technique with financial cost accounting. This arose because exergy began to be viewed as a measure of the true quality or value of energy carriers [60,61], notwithstanding the 
recent criticisms of this view by Hammond [10] and Hammond \& Stapleton [21]. The combined approach with monetary costing has been described using various terms in the engineering literature: 'exergy accounting', 'exergy costing', or 'exergoeconomics'. Although the term 'thermoeconomics' is often used for this purpose, it also encompasses the combination of First Law energy analysis with financial costing; sometimes called 'heat economy' [3]. The idea of exergy costing actually stretches back to the early 1930s, when one of the American pioneers of engineering thermodynamics, Joseph Keenan, implicitly suggested that it be used as a means for apportioning costs from the cogeneration of steam heating and power: CHP schemes in European terminology. However, it was only in the 1980s and 1990s that exergy accounting procedures became formalised and more widely adopted [3] led by the pioneering research of George Tsatsaronis and his co-workers, amongst others).

Exergoeconomics attributes unit costs to the exergy associated with each of the material and energy streams entering or leaving an engineering device, or its subsystems [62]; a procedure sometimes called the 'cost formation process' [3]. Exergy has been seen as providing a means for determining the sources of exergy losses, or 'irreversibilities', within thermal or chemical process plants. It is argued that the exergy function is closely related to the economic value of the carrier [61]; as users may be viewed as wishing to pay for the maximum useful work. Advocates assert that exergy destruction represents what the layperson views as 'waste' energy or heat [62]. Its cost is 'hidden', but no less important for that. The monetary costs are therefore allocated to system irreversibilities, and these are compared with (annualised) capital and operating costs for individual 'unit operations'. The mathematical formalism is provided within a general systems framework, and optimisation then yields possibilities for design changes and improvement [62]. It makes product costs, those associated with both capital equipment and exergy losses in process flow streams, and fuel savings more visible.

The various proposals to marry thermodynamic concepts with financial cost accounting represent attempts to couple what might be viewed as two incompatible disciplines. Economics claims to be 'normative', suggesting optimal courses of action, whereas thermodynamic analysis is 'descriptive'. Prices in economic markets are supposed to reflect value judgements, whilst exergy accounting deals only with essentially invariant 'costs'. The system boundaries are also arguably different: micro-economic units (such as the factory or the firm) versus an integrated supply chain encapsulated by the cradle-to-grave (or 'cradle-to-gate') concept. ['Arguably', since these tight boundaries are really a product of conventional accounting practices. Economic models, such as input-output matrices, can have wide boundaries - even wider than those of life-cycle models-although these may not be empirically realisable at fine levels of detail.] Exergoeconomics was therefore viewed by Hammond and Winnett [3] as attempting to blend "chalk and cheese". This is perhaps not surprising as the technique has been developed largely by specialist engineers and scientists talking amongst themselves. There is clearly a need to engage economists in a multidisciplinary discourse and to publish in the economics literature, as well as the engineering one. Nevertheless, this approach may yield practical benefits in terms of the optimisation of power plant even if the theoretical basis is open to question. Hammond and Ondo Akwe [63], for example, recently evaluated natural gas combined cycle power plants with and without carbon capture and storage using exergoeconomics. This yielded useful insights in terms of the most significant sources of exergy degradation and irreversibility. It illustrated that major improvements can potentially be achieved by considering power generation systems as a whole, rather than concentrating on enhancing the performance of individual components. 


\section{Concluding Remarks}

Thermodynamic concepts (such as energy, entropy, and exergy) have been utilised by researchers in a variety of disciplines with interests in environmental sustainability. Energy transformations within society have been viewed as mirroring resource depletion and environmental degradation by practitioners in, for example, ecology, economics and engineering. These consequences of human development are said to reflect thermodynamic ideas and methods of analysis; they are believed to mirror energy transformations within society. Mueller [15] drew an early parallel between the resource flows in economics and energy (as well as implicitly exergy) flows in thermodynamics. Such ideas have encouraged some $[8,13,14]$ to believe that thermodynamic principles or laws may act as a guide for engineers and others in the quest for environmental sustainability. Indeed, the property known as exergy is viewed as providing the basis of a tool for resource and/or emissions accounting even by various thermodynamicists $[3,10]$. It is also seen as indicating natural limits on the attainment of sustainability [10]. But these applications simply draw an analogy, or a metaphorical link, between one domain of study and another $[5,10,17]$. Caution therefore needs to be used when seeking real-world insights for ecological economics.

The significance of employing thermodynamic analysis in engineering and the physical sciences, and the insights it provides, are as useful today as they were when Albert Einstein advanced their merits. However, there is a tendency amongst a few thermodynamicists to elevate exergy analysis to a pivotal position in the array of technology assessment methods (see the discussion by Hammond and Stapleton [21]). Some US analysts, for example, view exergy as representing thermodynamic 'value', and regard the Second Law efficiency as the true efficiency. This is in effect to postulate an 'exergy theory of value'; analogous to the "monetary theory of value" in economics. It is not warranted, and Hammond and Stapleton [21] argue that it should be discouraged. Exergy is simply a measure of the maximum theoretical useful work that is obtainable from a thermal system (as it is brought into equilibrium with its surrounding environment) and this may not be the only, or necessarily most relevant, criteria in any given situation. Thus, exergy analysis should be employed as one tool amongst several quantitative approaches to study energy systems, in addition to the more traditional First Law energy analysis.

Thermodynamics methods of analysis can clearly form an important part of a 'sustainability toolkit', whilst economics and the environmental sciences will provide other complementary tools [3]. Energy and exergy analysis are 'descriptive' methods that highlight thermodynamic constraints in complex biological and physical systems. They also provide a means for evaluating the energy saving potential of various sectors of the economy and types of thermal plant. By contrast, economics as a 'normative' discipline, and its practitioners like to feel that it is the only technique or approach that is necessary to obtain an optimum solution. This is misguided (see Hammond and Stapleton [21]; Hammond and Winnett [3]), although there will clearly be economic and political barriers to the attainment of technical energy savings. It has been argued here that (i) exergy is a more easily understood thermodynamic property than is entropy to represent irreversibilities in complex systems; (ii) energy and exergy analysis need to be performed in parallel in order to accurately reflect the interrelated constraints imposed by the First and Second Laws; (iii) the behaviour of energy and matter are not equally mirrored by thermodynamic laws; (iv) thermodynamic insights for the economic process and 
natural resource scarcity are simply analogues or metaphors of reality; and (v) such insights should therefore be empirically tested against the real world. Georgescu-Roegen and other pioneers of ecological economics drew many valuable, qualitative insights from thermodynamics. But a new vocabulary for ecological economics is needed that stands on its own; one that evolves a unique terminology, rather than co-opt that of thermodynamics. The latter can mislead as much as enlighten when applied outside the realm of energy systems. In a similar vane, Mirowski [47] viewed Georgescu-Roegen's application of thermodynamic laws to economics as being "tantalisingly vague". In an attempt to 'close the circle' between thermodynamic and economic analysis, proposals have been made to couple the results of exergy analysis with financial cost accounting; yielding the so-called 'exergoeconomic' approach. Doubt has been cast on the use of exergoeconomic analysis by Hammond and Winnett [3], which they regard as attempting to merge the two qualitatively different approaches; one descriptive and the other normative. They argue that they may be in large measure incompatible-like trying to blend 'chalk and cheese'. Nevertheless, this approach may yield practical benefits in terms of the optimisation of power and process plant even if the theoretical basis is open to question.

\section{Acknowledgements}

In the present work an attempt is made by an engineering thermodynamicist (GPH) and an environmental economist (ABW) to address the influence of thermodynamic ideas on the development of 'ecological economics' from an interdisciplinary perspective. It is a revised and updated version of a paper originally presented at the Ecological Economics Session of the 'Complexity, Science \& Society' Conference held in Liverpool (UK), 11-14 September 2005. The first author's research (GPH) on the thermodynamics of low carbon energy systems is currently supported by a series of UK research grants awarded by various bodies. Firstly, the Engineering and Physical Sciences Research Council (EPSRC) has provided support as part of the SUPERGEN 'Highly Distributed Energy Futures' (HiDEF) Consortium. [The second author (ABW) is a Co-Investigator of this project.] This consortium has been co-ordinated by Graeme Burt and David Infield; both now with the Institute for Energy and Environment at the University of Strathclyde. Secondly, Geoffrey P. Hammond is receiving funding under the research programme of the UK Energy Research Centre (UKERC); Phase II renewed in 2009. This national centre is funded by three of the UK Research Councils-the Economic and Social Research Council (ESRC), the EPSRC, and the Natural Environment Research Council (NERC). He is grateful to Jim Skea (UKERC Research Director) and Nick Eyre (who was a UKERC Co-Director and co-ordinated its 'Energy Demand' Theme at the time of this study) for their support in this regard. Thirdly, he is presently himself jointly leading a large consortium of university partners (with Peter Pearson, an energy economist from Imperial College London) funded via the strategic partnership between e.on UK (the electricity generator) and the EPSRC to study the role of electricity within the context of 'Transition Pathways to a Low Carbon Economy'. Finally, he is the Director of the 'Energy Analysis and Environmental Life Cycle Assessment' Theme of the Biotechnology and Biological Sciences Research Council (BBSRC) Sustainable Bioenergy Centre (BSBEC), under a programme led by Katherine Smart of the University of Nottingham. Geoffrey P. Hammond and, where appropriate, Adrian B. Winnett are grateful to all these colleagues for their role 
in the co-ordination of large consortia of university and other partners. However, the views expressed in this paper are those of the authors alone, and do not necessarily reflect the views of the collaborators or the policies of the funding bodies. The authors wish to acknowledge the care with which Gill Green (Department of Mechanical Engineering, University of Bath) prepared the figures.

The authors' names appear alphabetically.

\section{References and Notes}

1. Snow, C.P. The Two Cultures; Cambridge University Press; Cambridge, UK, 1993. [A combined reprinting of his 1959 Rede Lecture at Cambridge: The Two Cultures and the Scientific Revolution, and his 1963 The Two Cultures: A Second Look, together with a new Introduction by Stefan Collini.]

2. Hammond, G.P. Science, sustainability and the establishment in a technological age. Interdisciplin. Sci. Rev. 2004, 29, 193-208.

3. Hammond, G.P.; Winnett, A.B. Interdisciplinary perspectives on environmental appraisal and valuation techniques. Waste Resource Manag. 2006, 159, 117-130.

4. Winnett, A. Environmental economics. In The Elgar Companion to Post Keynesian Economics; King, J., Ed.; Edward Elgar: Cheltenham, UK, 2003; pp. 122-126.

5. Söllner, F. A reexamination of the role of thermodynamics for environmental economics. Ecol. Econ. 1997, 22, 175-201.

6. Georgescu-Roegen, N. The Entropy Law and the Economic Process; Harvard University Press: Cambridge, MA, USA, 1971.

7. World Commission on Environment and Development. Our Common Future; Oxford University Press: Oxford, UK, 1987.

8. Parkin, S. Sustainable development: the concept and the practical challenge. Proc. Inst. Civil Eng. -Civil Eng. 2000, 138, 3-8.

9. Hammond, G.P. Energy, environment and sustainable development: a UK perspective. Process Saf. Environ. Prot. 2000, 78, 304-323.

10. Hammond, G.P. Engineering sustainability: thermodynamics, energy systems, and the environment. Int. J. Energ. Res. 2004, 28, 613-639.

11. Clift, R. The challenge for manufacturing. In Engineering for Sustainable Development; McQuaid, J., Ed.; Royal Academy of Engineering: London, UK, 1995; pp. 82-87.

12. Thring, M.W. Engineering in a stable world. Science, Technology and Development 1990, 8, 107-121.

13. Porritt, J. Playing Safe: Science and the Environment; Thames \& Hudson: London, UK, 2000.

14. Broman, G.; Holmberg, J.; Robèrt, K.H. Simplicity without reduction: thinking upstream towards the sustainable society. Interfaces 2000, 30, 13-25.

15. Mueller, R.F. Thermodynamics of Environmental Degradation. In Proceedings of the Annual Meeting of the American Geophysical Union, Washington, DC, USA, 15-16 June 1971.

16. Scott, W.; Gough, S. Sustainable Development and Learning: Framing the Issues; RoutledgeFalmer: London, UK, 2003. 
17. Mirowski, P. More Heat than Light: Economics as Social Physics, Physics as Nature's Economics; Cambridge University Press: Cambridge, UK, 1989.

18. Kline, S.J. The Low-Down on Entropy and Interpretive Thermodynamics; DCW Industries: La Cañada, CA, USA, 1999.

19. Hammond, G.P. Book review: Kline, S.J., the low-down on entropy and interpretive thermodynamics. Proc. Inst. Mech. Eng. A-J. Power 2003, 217, 337-339.

20. Upham, P. Scientific consensus on sustainability: the case of The Natural Step. Sustain. Dev. 2000, 8, 180-190.

21. Hammond, G.P.; Stapleton, A.J. Exergy analysis of the United Kingdom energy system. Proc. Inst. Mech. Eng. A-J. Power 2001, 215, 141-162.

22. Spalding, D.B.; Cole, E.H. Engineering Thermodynamics, 3rd ed.; Edward Arnold: London, UK, 1973.

23. Slesser, M. Energy in the Economy; Macmillan: London, UK, 1978.

24. Hammond, G.P.; Jones, C.I. Embodied energy and carbon in construction materials. Proc. Inst. Civil Eng-Energ. 2008, 161, 87-98.

25. Chapman, P.F. Methods of energy analysis. In Aspects of Energy Conversion; Blair, I.M., Jones, B.D., van Horn, A.J., Eds.; Pergamon: Oxford, UK, 1976; pp. 739-758.

26. Rosen, M.A.; Dincer, I. Sectoral energy and exergy modelling of Turkey. J. Energ. Resour. Technol. 1997, 119, 200-204.

27. van Gool, W. Exergy analysis of industrial processes. Energy 1992, 17, 791-803.

28. Dunbar, W.R.; Lior, N. Sources of combustion irreversibility. Combust. Sci. Technol. 1994, 103, 41-61.

29. Wall, G. Exergy conversion in Swedish society. Resour. Energ. 1987, 9, 55-73.

30. Reistad, G.M. Available energy conversion and utilisation in the United States. J. Eng. Power 1975, 97, 429-434.

31. van Gool, W. The value of energy carriers. Energy 1987, 12, 509-518.

32. Hammond, G.P. Alternative energy strategies for the United Kingdom revisited; market competition and sustainability. Technol. Forecast. Soc. Change 1998, 59, 131-151.

33. Hammond, G.P. Industrial energy analysis, thermodynamics and sustainability (In memoriam: Willem van Gool). Appl. Energ. 2007, 84, 675-700.

34. van Gool, W. Energy policy: fairy tales and factualities. In Innovation and Technology: Strategies and Policies; Soares, O.D.D., Martins da Cruz, A., Pereira, G.C., Soares, I.M.R.T., Reis, A.J.P.S., Eds.; Kluwer: Dordrecht, the Netherland, 1997; pp. 93-105.

35. Hammond, G.P. Towards sustainability: energy efficiency, thermodynamic analysis, and the "two cultures". Energ. Policy 2004, 32, 1789-1798.

36. Bilgen, E. Exergetic and engineering analyses of gas turbine based cogeneration systems. Energy 2000, 25, 1215-1229.

37. Haynie, D.T. Biological Thermodynamics; Cambridge University Press: Cambridge, UK, 2001.

38. Hammond, G.P. The use and abuse of thermodynamic ideas: to be or entropy... Proceedings of the Bath Royal Literary \& Scientific Institution 2004, 8, 235-236 [Summary (by Pepperdine, A.) of the presentation given to the BRLSI Science Group on 24 October 2003]. 
39. Costanza, R.; Daly, H.E. Natural capital and sustainable development. Conserv. Biol. 1992, 6, $37-46$.

40. Common, M.S.; Perrings, S.C. Towards an ecological economics of sustainability. Ecol. Econ. 1992, 6, 7-31.

41. Odum, H.T. Energy, ecology, and economics. AMBIO 1973, 2, 220-227.

42. Hammond, G.P. Energy and sustainability in a complex world: reflections on the ideas of Howard T. Odum. Int. J. Energ. Res. 2007, 31, 1105-1130.

43. Odum, H.T. Energy systems and the unification of science. In Maximum Power: The Ideas and Applications of H.T. Odum; Hall, C.A.S., Ed.; University Press of Colorado: Bouler, CO, USA, 1995; pp. 365-372.

44. Costanza, R. Embodied energy and economic valuation. Science 1980, 210, 1219-1224.

45. Georgescu-Roegen, N. Energy analysis and economic valuation. Southern Econ. J. 1979, 45, 1023-1058.

46. Georgescu-Roegen, N. The Entropy Law and the Economic Process in retrospect. Eastern Econ. J. 1986, 12, 3-25.

47. Mirowski, P. Energy and energetics in economic theory: a review essay. J. Econ. Issue. 1988, 12, 811-830.

48. van Gool, W. Thermodynamics aspects of energy conversion. Energy 1980, 5, 783-792.

49. Phung, D.L.; van Gool, W. Analyzing industrial energy conservation policies: the method of cost-energy dynamics. Energy Systems and Policy 1982, 6, 1-43.

50. Cleveland, C.J.; Ruth, M. When, where, and by how much do biophysical limits constrain the economic process? Ecol. Econ. 1997, 22, 203-223.

51. Jaffe, A.B.; Stavins, R.N. The energy efficiency gap: what does it mean? Energ. Policy 1994, 22, 804-811.

52. Energy and Time in the Economic and Physical Sciences; van Gool, W., Bruggink, J.J.C., Eds.; North-Holland: Amsterdam, The Netherlands, 1985.

53. Mayumi, K.; Gowdy, J.M. Bioeconomics and Sustainability: Essays in Honor of Nicholas Georgescu-Roegen; Edward Elgar: Cheltenham, UK, 1999.

54. Daly, H.E. On Nicholoas Georgescu-Roegen's contributions to economics: an obituary essay. Ecol. Econ. 1995, 13, 149-154.

55. Maneschi, A.; Zamagni, S. Nicholoas Georgescu-Roegen, 1906-1994. Econ. J. 1997, 107, 695-707.

56. Gillett, S.L. Entropy and its misuse, I. Energy, free and otherwise. Ecol. Econ. 2006, 56, 58-70.

57. Lozada, G.A. Entropy, free energy, work, and other thermodynamic variables in economics. Ecol. Econ. 2006, 56, 71-78.

58. Ayres, R.U. The second law, the fourth law, recycling and limits to growth. Ecol. Econ. 1999, 29, 473-483.

59. Ayres, R.U. Eco-thermodynamics: economics and the second law. Ecol. Econ. 1998, 26, 189-209.

60. Gagglioli, R.A. Thermodynamics: Second Law Analysis; American Chemical Society: Washington, DC, USA, 1980.

61. Tsatsaronis, G. Thermoeconomic analysis and optimisation of energy systems. Prog. Energ. Combust. Sci. 1993, 19, 227-237. 
62. Tsatsaronis, G.; Winhold, M. Exergoeconomic analysis and evaluation of energy-conversion plants-I. A new general methodology. Energy 1985, 10, 69-80.

63. Hammond, G.P.; Ondo Akwe, S.S. Thermodynamic and related analysis of natural gas combined cycle power plants with and without carbon sequestration. Int. J. Energ. Res. 2007, 31, 1180-1201.

(C) 2009 by the authors; licensee Molecular Diversity Preservation International, Basel, Switzerland. This article is an open-access article distributed under the terms and conditions of the Creative Commons Attribution license (http://creativecommons.org/licenses/by/3.0/). 